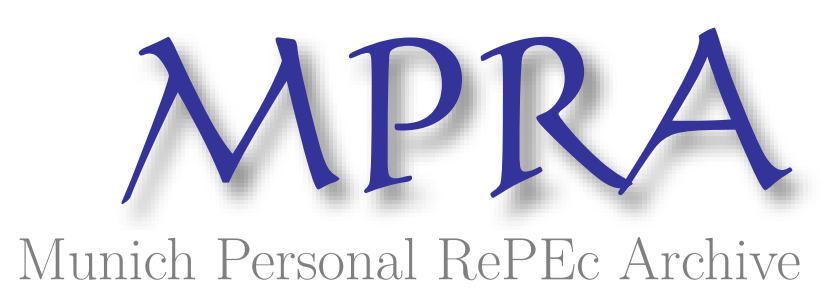

\title{
Price Stability In Small Open Economies
}

Dmitriev, Mikhail and Hoddenbagh, Jonathan

Boston College

November 2012

Online at https://mpra.ub.uni-muenchen.de/46118/

MPRA Paper No. 46118, posted 12 Apr 2013 08:04 UTC 


\title{
Price Stability in Small Open Economies*
}

\author{
Mikhail Dmitriev ${ }^{\dagger}$ and Jonathan Hoddenbagh ${ }^{\ddagger}$ \\ First Draft: November, 2012 This Version: February, 2013
}

We study the conduct of monetary policy in a continuum of small open economies. We solve the model globally in closed form without restricting the elasticity of substitution between home and foreign goods to one. Using this global closed-form solution, we give an exact characterization of optimal monetary policy and welfare with and without international policy cooperation. We consider the cases of internationally complete asset markets and financial autarky, producer currency pricing and local currency pricing. Under producer currency pricing, it is always optimal to mimic the flexible-price equilibrium through a policy of price stability. Under local currency pricing, policy should fix the exchange rate. Even if substitutability differs from one, the continuum of small open economies implies that the share of each country's output in the world consumption basket (and therefore the impact of the country's monopoly power) is negligible. This removes the incentive to deviate from price stability under producer currency pricing or a fixed exchange rate under local currency pricing. There are no gains from international monetary cooperation in all cases examined. Our results stand in contrast to those in the literature on optimal monetary policy for large open economies, where strategic interactions drive optimal policy away from price stability or fixed exchange rates, and gains from cooperation are present, when substitutability differs from one.

Keywords: Open economy macroeconomics; Optimal monetary policy; Price stability.

JEL Classification Numbers: E50, F41, F42.

\footnotetext{
*This paper grew out of our shared experience in the International Macroeconomics course taught by Fabio Ghironi. It is impossible to express our gratitude to him in words. We thank Pierpaolo Benigno, Bob King, Eyal Dvir, Susanto Basu and Peter Ireland for helpful comments. We also thank seminar participants at the BC/BU Green Line Macro Meeting. Any errors are our own.

$\dagger$ Department of Economics, Boston College, Chestnut Hill MA, 02467. E-mail: dmitriev@bc.edu.

${ }^{\ddagger}$ Department of Economics, Boston College, Chestnut Hill MA, 02467. E-mail: jon.hoddenbagh@gmail.com.
} 


\section{Introduction}

Price stability is widely viewed as a benchmark monetary policy for central banks, and has been found to be optimal in many closed economy studies. ${ }^{1}$ However, there is a longstanding debate over the desirability of price stability in the open economy. Asymmetric shocks, current account imbalances, cross-border pricing decisions, terms of trade movements, strategic interaction between countries, policy cooperation and other elements unique to the open economy introduce complications that are not present in the closed economy. These additional ingredients present a challenge for understanding optimal policy in the open economy.

In the classic case of producer currency pricing (PCP), exchange rate fluctuations passthrough into imported goods prices one-for-one. Under PCP, the first generation of microfounded models proved that a central bank should mimic the flexible price allocation, emphasizing the isomorphism between optimal monetary policy in closed and open economies (Clarida, Gali and Gertler (2002) and Obstfeld and Rogoff (2002)). But the optimality of price stability hinged on two crucial assumptions: unitary elasticity of substitution between home and foreign goods, and PCP. Unitary elasticity implies complete risk-sharing across countries via terms-of-trade movements, so that households face no idiosyncratic consumption risk in complete markets, incomplete markets or financial autarky (Cole and Obstfeld (1991)). Counterfactually, under unitary elasticity export revenues are constant and immune to exchange rate fluctuations and productivity shocks. No expenditure switching occurs, so that household consumption does not shift to goods from "cheaper" countries (countries with a depreciated currency for example).

Benigno and Benigno (2003) relaxed this assumption, and showed that price stability is no longer optimal for PCP under non-unitary elasticity. Their work affirmed a central bank's incentive to manipulate its terms of trade, removing the isomorphism between optimal monetary policy in closed and open economies. ${ }^{2}$ In addition, a number of studies have shown that under local currency pricing (LCP), when exchange rate fluctuations do not pass-through into imported goods prices, price stability is not optimal (Devereux and Engel (2003), Corsetti and

\footnotetext{
${ }^{1}$ In this paper, we refer to price stability as the policy which implements the flexible price allocation. A nonexhaustive list of papers finding price stability to be optimal in closed economies includes Goodfriend and King (1997, 2001), King and Wolman (1998), and Woodford (2000, 2002). See Schmitt-Grohé and Uribe (2011) for a recent survey. A counterexample is provided by multi-sector models such as that in Aoki (2001).

${ }^{2}$ Benigno and Benigno (2003) hearkened back to the earlier predictions of non-microfounded models, which established a deflationary bias in the open economy due to a central bank's incentive to appreciate its terms of trade (Rogoff (1985), Oudiz and Sachs (1984), and Canzoneri and Henderson (1990)). Benigno and Benigno (2006) later showed that price stability is optimal for large open economies under non-unitary elasticity when central banks cooperate and markets are complete. Corsetti, Dedola and Leduc (2010) also examine optimal monetary policy under financial autarky, and show that price stability is never optimal in financial autarky for large open economies. This contrasts with our results for small open economies, where price stability is optimal under PCP in all cases, even in financial autarky.
} 
Pesenti (2005), Corsetti, Dedola and Leduc (2010)). ${ }^{3}$

In this paper, we study the theoretical conditions under which price stability is optimal in a continuum of small open economies. We solve the model globally in closed form without restricting the elasticity of substitution between home and foreign goods to one. To the best of our knowledge, we derive the first closed-form solution for an open economy model that allows substitutability to differ from one, enabling us to consider cases away from perfect risk-sharing, including financial autarky. As in Benigno and Benigno (2003, 2006), Corsetti and Pesenti (2001, 2005), Devereux and Engel (2003), Sutherland (2004) and others, we assume one-period in advance price setting and no home bias.

While previous studies of optimal monetary policy in small open economies focus on PCP with non-cooperative policymakers, we give an exact characterization of optimal monetary policy and welfare with and without international policy cooperation for PCP and LCP, in complete markets and financial autarky. ${ }^{4}$ The continuum framework allows us to examine the implications of international policy cooperation and solve for Nash equilibria, which is not possible in the standard small open economy setup where there is only one measure zero small open economy and one "rest of the world" block. Combined with our closed form solution, we obtain exact welfare gains resulting from cooperation amongst a continuum of small, interdependent economies. ${ }^{5}$

Our results point to the importance of country size in the conduct of optimal monetary policy. We prove that for small open economies implementing the flexible price allocation through a policy of price stability is optimal under PCP, while a fixed exchange rate is optimal under LCP. Both results hold for any elasticity of substitution between home and foreign goods, in complete markets and financial autarky, with or without international policy cooperation. We

\footnotetext{
${ }^{3}$ Devereux and Engel (2003) study optimal monetary policy for two large open economies under PCP and LCP in a complete markets model with unitary elasticity and find that a fixed exchange rate is the optimal policy under LCP. Corsetti, Dedola and Leduc (2010) examine LCP under non-unitary elasticity in complete markets and financial autarky for cooperative policymakers, and show that a fixed exchange rate is not optimal. We do the same exercise for small open economies and find that a fixed exchange rate is optimal for LCP in all cases examined, for any elasticity.

${ }^{4} \mathrm{~A}$ non-exhaustive list of studies of optimal monetary policy in small open economies includes Gali and Monacelli (2005), Faia and Monacelli (2008), De Paoli (2009), Catao and Chang (2012), Hevia and Nicolini (2012) and Monacelli (2012). Generally, these papers allow for a richer specification and show various results depending on the emphasis and specific ingredients. All focus on PCP and do not examine potential gains from cooperation. Modeling LCP in a continuum of small open economies is quite difficult because the law of one price and purchasing power parity no longer hold. With two economies, it is not hard to keep track of exchange rate policy, but in the continuum this proves more challenging.

${ }^{5}$ To the best of our knowledge, we are the first to examine cooperation within the continuum framework. Our analysis does not face the problems encountered when conducting such an exercise in a log-linear model. In a log-linear model, the steady state will be different in cooperative and non-cooperative equilibria. As such, it is not clear how to make an accurate comparison of welfare between cooperative and non-cooperative regimes. This is one reason why there was such an emphasis on closed-form solutions in the early microfounded literature on international policy cooperation. See Corsetti and Pesenti (2001, 2005) and Obstfeld and Rogoff $(2001,2002)$. In this paper we focus only on monetary policy cooperation, but in a related paper we consider optimal fiscal policy and fiscal cooperation across countries (Dmitriev and Hoddenbagh (2013)).
} 
also show that international monetary cooperation does not improve welfare for small open economies. Under central bank commitment, the cooperative and non-cooperative solutions exactly coincide under any combination of PCP, LCP, complete markets and financial autarky for any elasticity of substitution. ${ }^{6}$

The driving force behind our results is the absence of strategic interaction among policymakers due to their small size in proportion to the rest of the world. Even when substitutability is different from one, the share of each country's output in the world consumption basket, and therefore the impact of the country's monopoly power, is negligible. Small open economies are analogous to firms in a model of monopolistic competition: policymakers have market power but cannot influence the behavior of other countries in the model. Strategic interactions between countries are thus absent.

The absence of strategic interaction has very different implications under PCP and LCP. Under PCP, the policy decisions of small open economies have no effect on consumption baskets in foreign countries, which shuts down the expenditure switching channel abroad. Unable to induce expenditure switching or influence foreign income, policymakers charge a constant terms of trade markup, utilizing monopoly power at the country level. Monopolistic producers in our model also charge a constant markup utilizing their monopoly power at the firm level within each country, but policymakers remove this domestic markup via production subsidies. Since monetary policy can only affect the variance and not the level of these constant markups, the optimal solution for the policymaker under PCP is to mimic the flexible price allocation.

In contrast, when economies are large, policymakers must internalize the effect of their decisions on the rest of the world. When domestic policymakers charge higher markups, foreign households become poorer and shift consumption toward cheaper products. Under PCP, expenditure switching abroad forces policymakers in large economies to behave more cooperatively and charge lower markups. Since the relative size of an economy changes stochastically with productivity shocks, the domestic policymaker in a large open economy finds it optimal to deviate from flexible prices and charge a variable markup rather than a constant one.

Under LCP, prices are fixed one period in advance in the currency of the importer, so the proportion of income allocated to country-specific goods is insulated from monetary policy and exogenous shocks. As a result, a constant proportion of world income is spent on each country's unique variety, and expenditure switching does not occur. In addition, small open economies cannot affect world income, so domestic output and labor are unaffected by monetary policy. The central bank thus maximizes welfare by stabilizing domestic consumption via a fixed exchange rate. With a fixed exchange rate, labor fluctuates with productivity shocks

\footnotetext{
${ }^{6}$ This matches results for large economies under unitary elasticity (Obstfeld and Rogoff (2002)), where gains from cooperation are absent, but contrasts with results for large open economies under non-unitary elasticity (Benigno and Benigno (2006), Corsetti et al (2010) and Sutherland (2004)), where gains are present.
} 
while consumption remains constant.

In contrast, monetary policy in large open economies can influence domestic labor under LCP. Expansionary monetary policy at home will increase wages, while goods prices remain fixed. This induces home and foreign households to work more, since domestic and foreign firms face higher demand for their goods. Higher real wages and an increase in hours worked lead to higher domestic consumption. Policymakers in large open economies thus face a trade-off between labor and consumption volatility. In such cases, a fixed exchange rate is no longer optimal. ${ }^{7}$

The paper proceeds as follows. We begin by laying out the model for PCP in Section 2. In Section 3, we examine optimal monetary policy in the closed economy to develop intuition, and then move to the open economy where we solve for optimal monetary policy under PCP, first in complete markets and then in financial autarky. Finally, we lay out the model for LCP in Section 4, and solve for optimal monetary policy in complete markets and financial autarky. Section 5 concludes.

\section{The Model}

We consider a continuum of small open economies represented by the unit interval, as popularized in the literature by Gali and Monacelli (2005). ${ }^{8}$ Each economy consists of a representative household and a representative firm. All countries are identical ex-ante: they have the same preferences, technology, and price-setting. Ex-post, economies will differ depending on the realization of their technology shock. Households are immobile across countries, however goods can move freely across borders. Each economy produces one final good, over which it exercises a degree of monopoly power. This is crucially important: countries are able to manipulate their terms of trade even though they are measure zero. However, because countries are small there will be no strategic interaction. As explained in the introduction, the expenditure switching effect and the ability to influence foreign income are both absent when economies are small. Policymakers will thus charge a constant terms of trade markup on their exports.

We use one-period-in-advance price setting to introduce nominal rigidities. ${ }^{9}$ Monopolistic firms set next-period's nominal prices, in terms of domestic currency, prior to next-period's production and consumption decisions. These firms will charge a constant markup in the flexprice equilibrium, utilizing their monopoly power at the firm level. Given this preset price, firms supply as much output as demanded by households.

\footnotetext{
${ }^{7}$ Unless labor enters the utility function as a linear term, as in Devereux and Engel (2003), in which case a fixed exchange rate is optimal. In our model, labor enters the utility function as a non-linear term but we still find that a fixed exchange rate is optimal under LCP.

${ }^{8} \mathrm{~A}$ similar version of this model appears in Dmitriev and Hoddenbagh (2013) where we employ wage rigidity instead of price rigidity and study the optimal design of a fiscal union within a currency union.

${ }^{9}$ Assuming rigid wages or prices has no impact on the results: they yield identical policy implications.
} 
We lay out a general framework below, and then hone in on two specific cases: complete markets and financial autarky. To avoid additional notation, we ignore time subindices unless absolutely necessary. When time subindices are absent, we are implicitly referring to period $t$.

Households In each economy $i \in[0,1]$, there is a representative household with lifetime expected utility

$$
\mathbb{E}_{t-1}\left\{\sum_{k=0}^{\infty} \beta^{k}\left(\frac{C_{i t+k}^{1-\sigma}}{1-\sigma}-\chi \frac{N_{i t+k}^{1+\varphi}}{1+\varphi}\right)\right\}
$$

where $\beta<1$ is the household discount factor, $C$ is the consumption basket or index, and $N$ is household labor effort (think of this as hours worked). Households face a general budget constraint that nests both complete markets and financial autarky; we will discuss the differences between the two in subsequent sections. For now, it is sufficient to simply write out the most general form of the budget constraint:

$$
C_{i t}=\left(1-\tau_{i}\right)\left(\frac{W_{i t}}{P_{i t}}\right) N_{i t}+D_{i t}+T_{i t}
$$

The non-distortionary tax rate on household labor income in country $i$ is denoted by $\tau_{i}$, while $T_{i t}$ is a lump-sum tax rebate to households. Net taxes equal zero in the model, as any amount of government revenue is rebated lump-sum to households. The consumer price index corresponds to $P_{i t}$, while the nominal wage is $W_{i t}$. $D_{i t}$ denotes state-contingent portfolio payments expressed in real consumption units, and can be written in more detail as:

$$
D_{i t} P_{i t}=\int_{0}^{1} \mathcal{E}_{i j t} B_{i j t} d j
$$

where $B_{i j t}$ is a state-contingent payment in currency $j .{ }^{10} \mathcal{E}_{i j t}$ is the exchange rate in units of currency $i$ per one unit of currency $j$; an increase in $\mathcal{E}_{i j t}$ signals a depreciation of currency $i$ relative to currency $j$. When international asset markets are complete, households perform all cross-border trades in contingent claims in period 0, insuring against all possible states in all future periods. The transverality condition simply states that all period 0 transactions must be balanced: payment for claims issued must equal payment for claims received. Leaving the details in the appendix, we use the following relationship as the transversality condition for complete markets:

$$
\mathbb{E}_{0}\left\{\sum_{t=0}^{\infty} \beta^{t} C_{i t}^{-\sigma} D_{i t}\right\}=0
$$

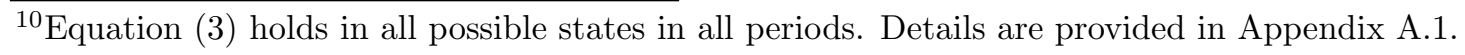


while in financial autarky

$$
D_{i t}=0
$$

Intuitively, the transversality condition (4) stipulates that the present discounted value of future earnings should be equal to the present discounted value of future consumption flows. Under complete markets, consumers choose a state contingent plan for consumption, labor supply and portfolio holdings in period 0 .

Consumption and Price Indices Households in each country consume a basket of imported goods. This consumption basket is an aggregate of all of the varieties produced by different countries. The consumption basket for a representative small open economy $i$, which is common across countries, is defined as follows:

$$
C_{i}=\left[\int_{0}^{1} c_{i j}^{\frac{\gamma-1}{\gamma}} d j\right]^{\frac{\gamma}{\gamma-1}}
$$

where $c_{i j}$ is the consumption by country $i$ of the final good produced by country $j$, and $\gamma$ is the elasticity of substitution between domestic and foreign goods (the Armington elasticity). Because there is no home bias in consumption, countries will export all of the output of their unique variety, and import varieties from other countries to assemble the consumption basket.

Prices are defined as follows: upper case $P_{i j}$ denotes the price in country $i$ (in currency $i$ ) of the unique final good produced in country $j$, while $C P I_{i}$ is the aggregate consumer price index in country $i$. Given the above consumption index, the consumer price index will be:

$$
C P I_{i}=\left[\int_{0}^{1} P_{i j}^{1-\gamma} d j\right]^{\frac{1}{1-\gamma}} .
$$

Consumption by country $i$ of the unique variety produced by country $j$ is:

$$
c_{i j}=\left[\frac{P_{i j}}{C P I_{i}}\right]^{-\gamma} C_{i}
$$

We assume that producer currency pricing (PCP) holds, and that the law of one price (LOP) holds, so that the price of the same good is equal across countries when converted into a common currency. We define the nominal bilateral exchange rate between countries $i$ and $j, \mathcal{E}_{i j}$, as units of currency $i$ per one unit of currency $j$. LOP requires that:

$$
P_{i j}=\mathcal{E}_{i j} P_{j j}
$$

Given LOP and identical preferences across countries, PPP will also hold for all $i, j$ country 
pairs:

$$
C P I_{i}=\mathcal{E}_{i j} C P I_{j}
$$

The terms of trade for country $j$ will be:

$$
T O T_{j}=\frac{P_{\text {Exports from } j}}{P_{\text {Imports to } j}}=\frac{P_{j j}}{C P I_{j}},
$$

where $\mathrm{TOT}_{j}$ is defined as the home currency price of exports over the home currency price of imports. Since the domestic consumption basket is entirely composed of foreign inputs, the domestic CPI will be equal to the home currency price of imports. Now we can take (7), and using (8) and (9), solve for demand for country $j$ 's unique variety:

$$
Y_{j}=\int_{0}^{1} c_{i j} d i=\int_{0}^{1}\left[\frac{P_{i j}}{C P I_{i}}\right]^{-\gamma} C_{i} d i \stackrel{(8)+(9)}{=}\left[\frac{P_{j j}}{C P I_{j}}\right]^{-\gamma} \int_{0}^{1} C_{i} d i=T O T_{j}^{-\gamma} C_{w} .
$$

where $C_{w}$ is defined as the average world consumption across all $i$ economies, $C_{w}=\int_{0}^{1} C_{i} d i$.

Production Each economy $i$ consists of a group of intermediate goods producers, $h \in[0,1]$, who exercise monopoly power over their unique variety, and a perfectly competitive final goods exporter who aggregates the intermediates in CES fashion into a final export good. For simplicity, we assume that intermediates are non-tradable. Thus, each country will bundle its intermediates into one final export good. ${ }^{11}$ Figure 1 below illustrates the bundling of intermediates into a final export good, and the bundling of those exports into the household consumption basket. We differentiate between the markup on intermediate domestic goods $\left(\mu=\frac{\varepsilon}{\varepsilon-1}\right)$ and the markup on the final export $\operatorname{good}\left(\mu_{\gamma}=\frac{\gamma}{\gamma-1}\right)$, which is imposed only if policymakers decide

\begin{tabular}{|c|c|c|c|c|c|c|}
\hline Consumption Basket & & & & & & \\
\hline $\begin{array}{l}\text { Final Export Good } \\
\qquad \mu=\gamma /(\gamma-1)\end{array}$ & & Country i & 1 & 1 & Country j & \\
\hline $\begin{array}{l}\text { Intermediate Goods Firms } \\
\qquad \mu=\epsilon /(\epsilon-1)\end{array}$ & $\Gamma$ & \begin{tabular}{l|l} 
\\
$x=1$
\end{tabular} & Firm N & Firm 1 & +1 & Firm N \\
\hline
\end{tabular}
to manipulate their terms of trade.

Figure 1

\footnotetext{
${ }^{11}$ We assume non-tradable intermediates with a final tradable consumption good that aggregates those intermediates for simplicity. In Gali and Monacelli's (2005, 2008) setup, intermediate goods are tradable, such that every country's import consumption basket is made up of an infinite number of varieties imported from an infinite number of countries. This requires integrating over two continuums. While it is straightforward for us to maintain their setup, we prefer the tractable alternative: a final goods exporter bundles the domestically produced intermediates for export. In this way, each country produces only one unique variety, and we only need integrate over one continuum. This assumption does not change the results in any way. In both cases the household consumption basket in each country is made up of imported goods from all $i$ countries, which are themselves made up of intermediates produced domestically.
} 
Production of intermediates requires technology $Z_{i}$, which is common across firms within a country, and labor $N_{i}(h)$, which is unique to each firm. We do not need to assume a specific distribution for technology, a luxury afforded by our closed form solution. We do assume that technology is independent across time and across countries, but is identical across firms within the same country. Given this, the production function of a representative intermediate goods firm $h$ in country $i$ will be:

$$
y_{i}(h)=Z_{i} n_{i}(h)
$$

Because intermediate goods firms produce differentiated varities, they have monopoly power over their output, which leads to a markup in intermediate goods. Perfectly competitive final goods exporters aggregate the intermediate input of each firm, so that production of the representative final exporter in a specific country is:

$$
Y_{i}=\left[\int_{0}^{1} y_{i}(h)^{\frac{\varepsilon-1}{\varepsilon}} d h\right]^{\frac{\varepsilon}{\varepsilon-1}},
$$

where $\varepsilon$ is the elasticity of substitution between different intermediates, and $\mu=\frac{\varepsilon}{\varepsilon-1}$ is the markup. The price of the final good in country $i, P_{i i}$, will be a function of the nominal price for intermediate goods, $p_{i}(h)$ :

$$
P_{i i}=\left[\int_{0}^{1} p_{i}(h)^{1-\varepsilon} d h\right]^{\frac{1}{1-\varepsilon}} .
$$

Cost minimization by the perfectly competitive final goods exporter leads to the following demand for intermediates:

$$
y_{i}(h)=\left[\frac{p_{i}(h)}{P_{i i}}\right]^{-\varepsilon} Y_{i} .
$$

In summary, monopoly power may be exercised at the firm and the country level: at the firm level because of differentiated domestic varieties, and at the country level because each economy produces a unique variety for export. Policymakers can use this country-level monopoly power to manipulate their terms of trade. But again, because economies are small and cannot affect world income or induce expenditure switching abroad, policymakers will choose a constant terms of trade markup. Households and final goods exporters have no monopoly power and are perfectly competitive. ${ }^{12}$

\footnotetext{
${ }^{12}$ It is entirely plausible to shift the country-level monopoly power from the policymaker to the final goods exporter. All results will be exactly the same: terms of trade markups will be constant — just as in a model of monopolistic competition. As such, price stability will remain optimal under PCP.
} 
Intermediate goods firms will price their unique good one-period-in-advance according to the following condition, which results from profit maximization:

$$
p_{i t}(h)=\mu \frac{\mathbb{E}_{t-1}\left\{C_{i t}^{-\sigma} y_{i t}(h) \frac{W_{i t}}{Z_{i t} C P I_{i}}\right\}}{\mathbb{E}_{t-1}\left\{\frac{C_{i t}^{-\sigma} y_{i t}(h)}{C P I_{i t}}\right\}}
$$

Households maximize utility (1) subject to their budget constraint (2). The FOC with respect to labor will give the following household labor supply condition:

$$
\frac{W_{i t}}{C P I_{i t}}=\left(\frac{\chi}{1-\tau_{i}}\right) N_{i t}^{\varphi} C_{i t}^{\sigma}
$$

Firms are identical, so that in equilibrium $p_{i}(h)=P_{i i}$ and $y_{i}(h)=Z_{i} n_{i}(h)=Z_{i} N_{i}=Y_{i}$. Using the labor demand condition (15) and the labor supply condition (16), and the fact that prices are preset at time $t-1$, the labor market clearing condition will be:

$$
1=\left(\frac{\chi \mu}{1-\tau_{i}}\right) \frac{\mathbb{E}_{t-1}\left\{N_{i t}^{1+\varphi}\right\}}{\mathbb{E}_{t-1}\left\{C_{i t}^{-\sigma} Y_{i t} T O T_{i}\right\}} .
$$

This is the general labor market clearing condition; it holds in the closed economy and in the open economy for PCP. Under PCP, the demand for the unique variety (11) will give the following labor market clearing condition:

$$
1=\left(\frac{\chi \mu}{1-\tau_{i}}\right) \frac{\mathbb{E}_{t-1}\left\{N_{i t}^{1+\varphi}\right\}}{\mathbb{E}_{t-1}\left\{C_{i t}^{-\sigma} Y_{i t}^{\frac{\gamma-1}{\gamma}} C_{w t}^{\frac{1}{\gamma}}\right\}} .
$$

Taking the expectations operator out of (18) will give the flexible price equilibrium for PCP.

We now turn our attention to the difference between complete markets and financial autarky.

\subsection{Complete Markets}

In this section, we assume that agents in each economy trade a full set of domestic and foreign state-contingent assets. Households in all countries will maximize their utility (1), choosing consumption, leisure, money holdings, and a complete set of state-contingent nominal bonds, subject to (2).

Risk-Sharing Complete markets and PPP imply the following risk-sharing condition:

$$
\frac{C_{i t}^{-\sigma}}{C_{i t+1}^{-\sigma}}=\frac{C_{j t}^{-\sigma}}{C_{j t+1}^{-\sigma}} \quad \forall i, j
$$


which states that the ratio of the marginal utility of consumption at time $t$ and $t+1$ must be equal across all countries. Importantly, this condition does not imply that consumption is equal across countries. Consumption in country $i$ will depend on its initial asset position, monetary policy, the distribution of country-specific shocks, the covariance of global and local shocks, and other factors.

When the central bank in economy $i$ changes its policy, the consumption allocation in country $i$ may change as well. For example, monetary policy can affect the covariance between home production and world consumption, and this covariance will influence the level of household consumption even under complete markets. The risk-sharing condition (19) and the transversality condition (4) are both robust to changes in monetary policy. If we combine the two, the resulting goods market clearing condition will also be robust to changes in monetary policy. We solve for this condition in the appendix, and simply state the result below.

Lemma 1 When (4),(17), and (19) hold, consumption in country $i$ can be expressed as a function of world consumption.

$$
C_{i t}=\frac{\mathbb{E}_{t-1}\left\{\sum_{t=1}^{\infty} \beta^{t}\left[Y_{i t} C_{w t}^{-\sigma} T O T_{i t}\right]\right\}}{\mathbb{E}_{t-1}\left\{\sum_{t=1}^{\infty} \beta^{t} C_{w t}^{1-\sigma}\right\}} C_{w t} .
$$

Using the fact that $Z_{i t}$ is independent across time and and across countries, and prices are preset, (20) is equivalent to

$$
C_{i t}=\mathbb{E}_{t-1}\left\{Y_{i t} T O T_{i t}\right\}=C_{w t}^{\frac{1}{\gamma}} \mathbb{E}_{t-1}\left\{Y_{i t}^{\frac{\gamma-1}{\gamma}}\right\}
$$

\subsection{Financial Autarky}

The aggregate resource constraint under financial autarky specifies that the nominal value of output in the home country (exports) must equal the nominal of consumption in the home country (imports). That is, trade in goods must be balanced. In a model with cross-border lending, bonds would also show up in this condition, but in financial autarky, they are obviously absent. The primary departure from complete markets lies in the household and economy-wide budget constraints.

$$
\underbrace{P_{i i} \cdot Y_{i}}_{\text {Exports }}=\underbrace{C P I_{i} \cdot C_{i}}_{\text {Imports }}
$$

Using the fact that (11) holds under both complete markets and financial autarky, and substituting this into (22), one can show that demand for country $i$ 's good in financial autarky will be

$$
C_{i t}=C_{w t}^{\frac{1}{\gamma}} Y_{i t}^{\frac{\gamma-1}{\gamma}}
$$


Complete markets and autarky differ only by goods market clearing. In complete markets consumption is equal to expected domestic output expressed in consumption baskets; in autarky consumption is equal to realized domestic output expressed in consumption baskets.

\section{Optimal Monetary Policy}

Now that we've laid out the model in detail, for both complete markets and financial autarky, we consider optimal policy for a variety of scenarios. Without loss of generality, we assume a cashless limiting economy. ${ }^{13}$ Central banks will optimize by choosing labor instead of money supply or an interest rate rule, but all three are equivalent in this model: money supply will determine the interest rate, which will in turn determine labor. One can easily write down a money supply rule or interest rate rule that exactly implements the allocation resulting from optimization over labor. But for the sake of simplicity, we assume the central bank optimizes over labor.

The timing of the model is described in Figure 2 below. Before any shocks are realized, national central banks declare their policy for all states of the world. With this knowledge in hand, households lay out a state-contingent plan for consumption, labor, money and asset holdings. After that, shocks hit the economy. Note that under financial autarky, no international asset trading will occur.

\section{Figure 2}

$\begin{array}{cccc}-1 & 0 & 1 & 1\end{array}$

We begin with an analysis of optimal monetary policy in a closed economy version of our model, and then proceed to the open economy. In all cases, we consider optimal policy under commitment.

\subsection{Closed Economy}

\section{The Flexible Price Allocation}

To solve for the flexible price allocation in the closed economy, simply take expectations out of (17), set $T O T_{i}=1$, and use goods market clearing $\left(Y_{t}=C_{t}=N_{t} Z_{t}\right)$. This will give us a

\footnotetext{
${ }^{13}$ Benigno and Benigno (2003) describe a cashless-limiting economy in detail in their appendix, pp.756-758.
} 
system of two equations in two unknowns, $N_{t}$ and $C_{t}$ :

$$
\begin{aligned}
1 & =\left(\frac{\chi \mu}{1-\tau}\right) \frac{N_{t}^{1+\varphi}}{C_{t}^{1-\sigma}}, \\
C_{t} & =N_{t} Z_{t} .
\end{aligned}
$$

The solution to this two equation system is the flexible price allocation for the closed economy: $C_{t}=\left(\frac{1-\tau}{\chi \mu}\right)^{\frac{1}{\sigma+\varphi}} Z_{t}^{\frac{1+\varphi}{\sigma+\varphi}}$.

\section{Optimal Monetary Policy}

The central bank will choose labor to maximize the expected utility of the representative agent, given the closed economy labor market and goods market clearing constraints.

$$
\max _{N_{t}} \mathbb{E}_{t-1}\left\{\frac{C_{t}^{1-\sigma}}{1-\sigma}-\chi \frac{N_{t}^{1+\varphi}}{(1+\varphi)}\right\}
$$

s.t.

$$
\begin{aligned}
1 & =\left(\frac{\chi \mu}{1-\tau}\right) \frac{\mathbb{E}_{t-1}\left\{N_{t}^{1+\varphi}\right\}}{\mathbb{E}_{t-1}\left\{C_{t}^{1-\sigma}\right\}} \\
C_{t} & =Z_{t} N_{t}
\end{aligned}
$$

Although it is standard practice to use a welfare-loss function for optimal policy evaluation, we can simply use the household utility function because of our global, closed-form solution. ${ }^{14}$

Proposition 2 In the closed economy under ex ante commitment, the central bank will maximize (24) subject to (25) and (26). The solution to this problem is: $C_{t}=\left(\frac{1-\tau}{\chi \mu}\right)^{\frac{1}{\sigma+\varphi}} Z_{t}^{\frac{1+\varphi}{\sigma+\varphi}}$. Price stability is the optimal policy, as the central bank exactly replicates the flexible price allocation.

Proof See Appendix A.

\section{Optimal Policy Under A Social Planner}

Proposition 3 In the closed economy, the social planner will maximize (24) subject to (26), ignoring the labor condition (25). The solution to this problem is: $C_{t}=\left(\frac{1}{\chi}\right)^{\frac{1}{\sigma+\varphi}} Z_{t}^{\frac{1+\varphi}{\sigma+\varphi}}$. The social planner will replicate the flexible price allocation and remove the monopolistic markup, yielding the Pareto efficient allocation.

Proof See Appendix A.

\footnotetext{
${ }^{14}$ The only reason to use a welfare-loss function is if the model in question must be approximated around a steady state. Here, no such approximation is required, and thus a welfare-loss function is not needed.
} 
In comparing the solutions described in Proposition 1 and 2, notice that the social planner mimics the flexible price allocation while eliminating the monopolistic markup $\mu$ (Proposition 2 ), while the markup and labor tax remain when we only consider optimal monetary policy (Proposition 1). In the case of ex ante commitment in Proposition 1, a fiscal authority may introduce subsidies to exactly offset the markup and replicate the social planner equilibrium. It is straightforwad to show that $\tau=1-\mu$ will get rid of the monopolistic distortion on labor inputs and give the Pareto efficient allocation.

We've studied optimal policy in the closed economy, and proved the optimality of price stability. The divine coincidence holds, a well known result in the closed economy. One already sees the link between stable monopolistic markups and a desire to mimic the flexible price allocation. We now turn our attention to the open economy, where we prove that optimal monetary policy in closed and small open economies is isomorphic in both complete markets and financial autarky.

\subsection{Global Social Planner}

The global social planner is a benevolent "dictator" that distributes goods across countries in order to maximize aggregate world utility. This scenario is analogous to perfect cooperation among the social planner's of all $i$ countries. The global social planner solution defines the Pareto efficient allocation. Since the economies in our model are identical ex-ante, the global social planner will maximize a weighted utility function over all $i$ countries,

$$
\int_{0}^{1}\left[\frac{C_{i}^{1-\sigma}}{1-\sigma}-\chi \frac{N_{i}^{1+\varphi}}{(1+\varphi)}\right] d i
$$

subject to the consumption basket and the aggregate resource constraint:

$$
\begin{aligned}
C_{i} & =\left[\int_{0}^{1} c_{i j}^{\frac{\gamma-1}{\gamma}} d j\right]^{\frac{\gamma}{\gamma-1}} \\
Y_{i} & =Z_{i} N_{i}=\int_{0}^{1} c_{j i} d j .
\end{aligned}
$$

Proposition 4 The global social planner will maximize utility weighted over all $i$ countries 
(27), subject to (28) and (29). The solution to this optimization problem is:

$$
\begin{aligned}
& \mathbb{E}\left\{U_{i}\right\}=C_{i}^{1-\sigma}\left(\frac{1}{1-\sigma}-\frac{1}{1+\varphi}\right) \\
& C_{i}=\left(\frac{1}{\chi}\right)^{\frac{1}{\sigma+\varphi}} Z_{w}^{\frac{1+\varphi}{\sigma+\varphi}}, \\
& N_{i}=\left(\frac{1}{\chi}\right)^{\frac{1}{\sigma+\varphi}} Z_{w}^{\frac{(1-\gamma \sigma)(1+\varphi)}{(1+\gamma \varphi)(\sigma+\varphi)}} Z_{i}^{\frac{\gamma-1}{1+\gamma \varphi}}, \\
& Y_{i}=\left(\frac{1}{\chi}\right)^{\frac{1}{\sigma+\varphi}} Z_{w}^{\frac{(1-\gamma \sigma)(1+\varphi)}{(1+\gamma \varphi)(\sigma+\varphi)}} Z_{i}^{\frac{\gamma(1+\varphi)}{1+\gamma \varphi}} \\
& Z_{w}=\left(\int_{0}^{1} Z_{i}^{\frac{(\gamma-1)(1+\varphi)}{1+\gamma \varphi}} d i\right)^{\frac{1+\gamma \varphi}{(\gamma-1)(1+\varphi)}} .
\end{aligned}
$$

The global social planner solution exactly replicates the flexible price allocation while eliminating monopolistic markups, yielding the Pareto optimal allocation.

\section{Proof See Appendix A.}

The global social planner allocation above is a traditional benchmark for the evaluation of different policy regimes. Because this is the Pareto efficient allocation, it provides a natural marker with which to compare various policies under commitment. Notice that there are no markups in the Pareto efficient allocation: the benevolent global social planner has eliminated the markup on intermediate goods $\mu$, and resisted the temptation to manipulate the terms of trade. In the next sections we will look closely at optimal monetary policy for central banks and see what conditions are necessary to replicate the global social planner allocation.

\subsection{Complete Markets}

In this section we examine the optimal monetary policy for cooperative and non-cooperative central banks in complete markets. The objective functions for cooperative and non-cooperative central banks are below.

$$
\begin{aligned}
& \max _{N_{i t}} \mathbb{E}_{t-1}\left\{\frac{C_{i t}^{1-\sigma}}{1-\sigma}-\chi \frac{N_{i t}^{1+\varphi}}{1+\varphi}\right\} \\
& \max _{\forall N_{i t}} \int_{0}^{1}\left\{\frac{C_{i t}^{1-\sigma}}{1-\sigma}-\chi \frac{N_{i t}^{1+\varphi}}{1+\varphi}\right\} d i
\end{aligned}
$$

Non-cooperative central banks will choose the optimal amount of labor to maximize their domestic welfare (30a), while cooperative central banks will choose the optimal amount of labor in order to maximize the welfare of all $i$ economies (30b). In both cases, policymakers will maximize the appropriate objective function subject to labor market clearing (31) and 
goods market clearing (32) constraints, and production (33) and aggregate world consumption (34):

$$
\begin{aligned}
& 1=\left(\frac{\chi \mu}{1-\tau_{i}}\right) \frac{\mathbb{E}_{t-1}\left\{N_{i t}^{1+\varphi}\right\}}{\mathbb{E}_{t-1}\left\{C_{i t}^{-\sigma} Y_{i t}^{\frac{\gamma-1}{\gamma}} C_{w t}^{\frac{1}{\gamma}}\right\}}, \\
& C_{i t}=C_{w t}^{\frac{1}{\gamma}} \mathbb{E}_{t-1}\left\{Y_{i t}^{\frac{\gamma-1}{\gamma}}\right\} \\
& Y_{i t}=Z_{i t} N_{i t}, \\
& C_{w t}=\left(\int_{0}^{1} Y_{i t}^{\frac{\gamma-1}{\gamma}}\right)^{\frac{\gamma}{\gamma-1}} .
\end{aligned}
$$

Proposition 5 In complete markets, non-cooperative central banks will maximize (30a) and cooperative central banks will maximize (30b), subject to (31), (32), (33) and (34). The solution under commitment for both cooperative and non-cooperative central banks in complete markets is:

$$
\begin{aligned}
& \mathbb{E}\left\{U_{i}\right\}=C_{i}^{1-\sigma}\left(\frac{1}{1-\sigma}-\frac{1-\tau_{i}}{\mu(1+\varphi)}\right) \\
& C_{i}=\left(\frac{1-\tau_{i}}{\chi \mu}\right)^{\frac{1}{\sigma+\varphi}} Z_{w}^{\frac{1+\varphi}{\sigma+\varphi}} \\
& N_{i}=\left(\frac{1-\tau_{i}}{\chi \mu}\right)^{\frac{1}{\sigma+\varphi}} Z_{w}^{\frac{(1-\gamma \sigma)(1+\varphi)}{(1+\gamma \varphi)(\sigma+\varphi)}} Z_{i}^{\frac{\gamma-1}{1+\gamma \varphi}} \\
& Y_{i}=\left(\frac{1-\tau_{i}}{\chi \mu}\right)^{\frac{1}{\sigma+\varphi}} Z_{w}^{\frac{(1-\gamma \sigma)(1+\varphi)}{(1+\gamma \varphi)(\sigma+\varphi)}} Z_{i}^{\frac{\gamma(1+\varphi)}{1+\gamma \varphi}} \\
& Z_{w}=\left(\int_{0}^{1} Z_{i}^{\frac{(\gamma-1)(1+\varphi)}{1+\gamma \varphi}} d i\right)^{\frac{1+\gamma \varphi}{(\gamma-1)(1+\varphi)}}
\end{aligned}
$$

The resulting equilibrium allocation exactly coincides with the flexible price allocation. Mimicking the flexible price allocation is thus the dominant strategy for non-cooperative central banks in complete markets, and is the optimal policy under cooperation.

Proof See Appendix A.

There are a few important points to note from this exercise. First of all, note that consumption in the optimal allocation is not subject to idiosyncratic technology shocks. Because we are in complete markets, consumption is simply a function of average world technology. Second, note that cooperative and non-cooperative equilibria are identical: both yield the flexible price allocation.

In complete markets, we've shown that small open economy central banks will mimic the flexible price allocation under both cooperative and non-cooperative regimes, for any elasticity 
of substitution between home and foreign goods. In addition, we've demonstrated that international monetary cooperation has no impact on welfare. This is because monetary policy has no power against non-contingent distortions like markups, and can only address the contingent price rigidity distortion. In the next section, we conduct the same exercise for financial autarky.

\subsection{Financial Autarky}

In financial autarky, the objective functions for cooperative and non-cooperative central banks will be identical to those in complete markets. The only difference in the optimization problem will be in the goods market constraint. In complete markets home consumption is a function of expected output (32), while in autarky home consumption is a function of actual output (36).

$$
\begin{aligned}
& 1=\left(\frac{\chi \mu}{1-\tau_{i}}\right) \frac{\mathbb{E}_{t-1}\left\{N_{i t}^{1+\eta}\right\}}{\mathbb{E}_{t-1}\left\{C_{i t}^{-\sigma} Y_{i t}^{\frac{\gamma-1}{\gamma}} C_{w, t}^{\frac{1}{\gamma}}\right\}} \\
& C_{i t}=C_{w, t}^{\frac{1}{\gamma}} Y_{i t}^{\frac{\gamma-1}{\gamma}} \\
& Y_{i t}=Z_{i t} N_{i t} \\
& C_{w t}=\left(\int_{0}^{1} Y_{i t}^{\frac{\gamma-1}{\gamma}}\right)^{\frac{\gamma}{\gamma-1}} .
\end{aligned}
$$

Proposition 6 In financial autarky, non-cooperative central banks will maximize (30a) and cooperative central banks will maximize (30b), subject to (35), (36), (37) and (38). The solution under commitment for both cooperative and non-cooperative central banks in financial autarky is:

$$
\begin{aligned}
& \mathbb{E}\left\{U_{i}\right\}=C_{i}\left(\frac{1}{1-\sigma}-\frac{1-\tau_{i}}{\mu(1+\varphi)}\right), \\
& C_{i}=\left(\frac{1-\tau_{i}}{\chi \mu}\right)^{\frac{1}{\sigma+\varphi}}\left(Z_{i}^{\gamma-1} Z_{w}^{\frac{1+\varphi}{\sigma+\varphi}}\right)^{\frac{1+\varphi}{1-\sigma+\gamma(\varphi+\sigma)}}, \\
& N_{i}=\left(\frac{1-\tau_{i}}{\chi \mu}\right)^{\frac{1}{\sigma+\varphi}}\left(Z_{i}^{\gamma-1} Z_{w}^{\frac{1+\varphi}{\sigma+\varphi}}\right)^{\frac{1-\sigma}{1-\sigma+\gamma(\varphi+\sigma)}}, \\
& Y_{i}=\left(\frac{1-\tau_{i}}{\chi \mu}\right)^{\frac{1}{\sigma+\varphi}}\left(Z_{i}^{\gamma-1} Z_{w}^{\frac{1+\varphi}{\sigma+\varphi}}\right)^{\frac{1-\sigma}{1-\sigma+\gamma(\varphi+\sigma)}} Z_{i}, \\
& Z_{w}=\left(\int_{0}^{1} Z_{i}^{\frac{(\gamma-1)(1+\varphi)}{1-\sigma+\gamma(\sigma+\varphi)}} d i\right)^{\frac{1-\sigma+\gamma(\sigma+\varphi)}{(\gamma-1)(1+\varphi)}} .
\end{aligned}
$$

The resulting equilibrium allocation exactly coincides with the flexible price allocation. Mimicking the flexible price allocation is thus the dominant strategy for non-cooperative central banks in financial autarky, and is the optimal policy under cooperation.

Proof See Appendix A. 
Note that in financial autarky, consumption is a function of idiosyncratic technology $Z_{i}$, reflecting the lack of international risk-sharing. As in complete markets, the optimal policy for cooperative and non-cooperative central banks is to mimic the flexible price equilibrium. We thus demonstrate the isomorphism between optimal monetary policy in closed and small open economies for both complete markets and financial autarky.

As we've stated before, the key to this isomorphism is the absence of strategic interaction when economies are small. Unable to influence foreign consumption or foreign income, policymakers in small open economies charge a constant terms of trade markup on their exports. Combined with monopolistic firms charging a constant markup, the optimal policy response is to remove price rigidities and return to the flexible price allocation. Similarly, when elasticity is unitary and economies are large, as in Clarida, Gali and Gertler (2002) and Obstfeld and Rogoff (2002), strategic interactions between countries are nullified by a lack of expenditure switching and complete risk-sharing via terms of trade movements, and price stability is optimal.

\section{Local Currency Pricing}

We now turn our attention to the case of LCP. Modeling LCP in a continuum of small open economies is difficult because the law of one price and purchasing power parity no longer hold. In two economy models, keeping track of exchange rate policy is trivial, but in the continuum this becomes challenging. Although we will gloss over many of the methodological nuances necessary to deal with LCP in the continuum, all modeling details can be found in Appendix B. To simplify expressions, we assume log utility $(\sigma=1)$, but allow $\varphi$ to vary as before.

Under LCP, firms price their export good one-period-in-advance in the currency of the importing country. As such, there is zero exchange rate pass-through into import prices. Each country's consumer price index will thus be fixed one-period-in-advance, as exchange rate movements will have no impact on import prices. When firms price in this way, the labor market and goods market clearing constraints will differ from those under PCP. In complete markets and financial autarky, goods and labor market clearing conditions for LCP are:

$$
\begin{aligned}
1 & =\left(\frac{\chi \mu}{1-\tau_{i}}\right) \frac{\mathbb{E}_{t-1}\left\{N_{i t}^{1+\varphi}\right\}}{\mathbb{E}_{t-1}\left\{C_{i t}^{-1} Y_{i t} T O T_{i t}\right\}}, \\
C_{i t} & =\frac{P_{0 i t}}{C P I_{i t}} \mathcal{E}_{i 0 t} Y_{i t} .
\end{aligned}
$$

To keep track of exchange rate policy in the continuum, we introduce the concept of a numeraire currency, which we assume is the currency of country 0 . Thus, $\mathcal{E}_{i 0 t}$ is the exchange rate between country $i$ and the numeraire country, and $P_{0 i t}$ is the import price of the numeraire country's good in currency $i$. 
Proposition 7 Under LCP, non-cooperative central banks will maximize (30a) subject to (39) and (40). A fixed exchange rate will be the Nash equilibrium policy for a non-cooperative central bank in both complete markets and financial autarky under LCP.

Proof See Appendix B.

$$
\begin{aligned}
\mathbb{E}_{t-1}\left\{C_{i t}^{-\sigma} Y_{i t} \mathcal{E}_{i 0 t}\right\} & =\frac{\chi \mu}{1-\tau_{i}} \frac{\mathbb{E}_{t-1}\left\{N_{i t}^{1+\varphi}\right\} \mathbb{E}_{t-1}\left\{C_{j t}\right\}}{\mathbb{E}_{t-1}\left\{\mathcal{E}_{0 j t} C_{j t}\right\}}, \\
C_{i t} & =\mathcal{E}_{i 0 t} \int_{0}^{1} C_{j t} \mathcal{E}_{0 j t} d j
\end{aligned}
$$

Proposition 8 Under LCP, cooperative central banks will maximize (30b) subject to (41) and (42). The optimal policy for cooperative central banks in both complete markets and financial autarky will be a fixed exchange rate.

\section{Proof See Appendix B.}

Price stability is no longer optimal under LCP. Instead, central banks should fix the exchange rate. Why is a fixed exchange rate optimal under LCP? As we discussed in the introduction, LCP insulates household consumption baskets in each country from exchange rate fluctuations, guaranteeing a constant proportion of world income spent on each unique import good because exchange rate fluctuations do not pass-through into imported goods prices. Policymakers in small open economies are also unable to influence world income. Therefore domestic output and labor are unaffected by monetary policy. Stabilizing consumption becomes the central bank's goal, and the policy mechanism to achieve this goal is a fixed exchange rate. With a fixed exchange rate, labor fluctuates with productivity shocks but consumption remains constant. In contrast, when economies are large, monetary policy can influence domestic labor under LCP. In such cases, a fixed exchange rate is no longer optimal as shown by Corsetti, Dedola and Leduc (2010). The reasons for this are outlined in the introduction.

\section{Conclusion}

We derive the first closed-form solution for an open economy model that does not restrict substitutability between home and foreign goods to one. Different from the standard modeling framework in the literature, we assume a continuum of small open economies interacting in general equilibrium, rather than two large open economies. The tractability of our framework requires simplifying assumptions along other dimensions. Prices are set one period in advance, and each country exports all of its production and imports varieties from all other countries to aggregate into a final consumption basket. Using this setup, we answer the following question: 
What are the theoretical conditions under which it is optimal for a central bank to mimic the flexible price allocation?

We prove that for PCP, small open economy central banks should mimic the flexible price allocation for any elasticity of substitution between home and foreign goods, in cooperative and non-cooperative equilibria, in both complete markets and financial autarky. Policymakers should focus solely on eliminating domestic price rigidities and ignore external factors such as exchange rate movements, even in the presence of monopolistic distortions in goods markets and terms of trade distortions which are not internalized by domestic producers. Under LCP, we show that small open economy central banks should fix their exchange rate. Our results contrast with those in the literature for large open economies, where it is not optimal to mimic the flexible price allocation under PCP or to fix the exchange rate under LCP when substitutability differs from one.

We also calculate the welfare gains from cooperation among national monetary authorities. We show that for any elasticity in PCP and LCP, in both complete markets and financial autarky, international monetary cooperation has no impact on welfare. Price stability is the dominant strategy for central banks under PCP, and is thus a Nash Equilibrium in both noncooperative and cooperative scenarios, while a fixed exchange rate is a Nash Equilibrium under LCP in both non-cooperative and cooperative scenarios. As a result, no benefits arise from cross-country monetary policy cooperation.

Our goal in this paper has been to provide a unifying framework for the analysis of optimal monetary policy in small open economies. We focus on the classic benchmark cases, PCP and LCP in both complete markets and financial autarky, to try and gain intuition and understanding about what differentiates policymaking in small and large open economies, particularly when risk sharing is not provided by terms of trade movements. 


\section{References}

[1] Kosuke Aoki. Optimal monetary policy responses to relative-price changes. Journal of Monetary Economics, 48(1):55-80, August 2001.

[2] Gianluca Benigno and Pierpaolo Benigno. Price stability in open economies. Review of Economic Studies, 70(4):743-764, October 2003.

[3] Gianluca Benigno and Pierpaolo Benigno. Designing targeting rules for international monetary policy cooperation. Journal of Monetary Economics, 53(3):473-506, April 2006.

[4] Matthew B. Canzoneri and Dale W. Henderson. Monetary Policy in Interdependent Economies: A Game-Theoretic Approach, volume 1 of MIT Press Books. The MIT Press, 1991.

[5] Luis Catao and Roberto Chang. Monetary rules for commodity traders. NBER Working Papers 18536, National Bureau of Economic Research, November 2012.

[6] Richard Clarida, Jordi Gali, and Mark Gertler. A simple framework for international monetary policy analysis. Journal of Monetary Economics, 49(5):879-904, July 2002.

[7] Harold L. Cole and Maurice Obstfeld. Commodity trade and international risk sharing : How much do financial markets matter? Journal of Monetary Economics, 28(1):3-24, August 1991.

[8] Giancarlo Corsetti, Luca Dedola, and Sylvain Leduc. Optimal monetary policy in open economies. In Benjamin M. Friedman and Michael Woodford, editors, Handbook of Monetary Economics, volume 3 of Handbook of Monetary Economics, chapter 16, pages 861-933. Elsevier, 2010.

[9] Giancarlo Corsetti and Paolo Pesenti. Welfare and macroeconomic interdependence. The Quarterly Journal of Economics, 116(2):421-445, May 2001.

[10] Giancarlo Corsetti and Paolo Pesenti. International dimensions of optimal monetary policy. Journal of Monetary Economics, 52(2):281-305, March 2005.

[11] Michael B. Devereux and Charles Engel. Monetary policy in the open economy revisited: Price setting and exchange-rate flexibility. Review of Economic Studies, 70(4):765-783, October 2003.

[12] Mikhail Dmitriev and Jonathan Hoddenbagh. Financial integration, fiscal unions and currency unions. 2013. 
[13] Ester Faia and Tommaso Monacelli. Optimal monetary policy in a small open economy with home bias. Journal of Money, Credit and Banking, 40(4):721-750, 062008.

[14] Jordi Galí and Tommaso Monacelli. Monetary policy and exchange rate volatility in a small open economy. Review of Economic Studies, 72(3):707-734, 072005.

[15] Marvin Goodfriend and Robert King. The new neoclassical synthesis and the role of monetary policy. In NBER Macroeconomics Annual 1997, Volume 12, NBER Chapters, pages 231-296. National Bureau of Economic Research, Inc, 1997.

[16] Marvin Goodfriend and Robert G. King. The case for price stability. NBER Working Papers 8423, National Bureau of Economic Research, Inc, August 2001.

[17] Constantino Hevia and Juan Pablo Nicolini. Optimal devaluations. 2012.

[18] Robert King and Alexander L. Wolman. What should the monetary authority do when prices are sticky? In Monetary Policy Rules, NBER Chapters, pages 349-404. National Bureau of Economic Research, Inc, 1999.

[19] Tommaso Monacelli. Is monetary policy in an open economy fundamentally different? 2012 .

[20] Maurice Obstfeld and Kenneth Rogoff. New directions for stochastic open economy models. Journal of International Economics, 50(1):117-153, February 2000.

[21] Maurice Obstfeld and Kenneth Rogoff. Global implications of self-oriented national monetary rules. The Quarterly Journal of Economics, 117(2):503-535, May 2002.

[22] Gilles Oudiz and Jeffrey Sachs. International policy coordination in dynamic macroeconomic models. NBER Working Papers 1417, National Bureau of Economic Research, Inc, August 1984.

[23] Bianca De Paoli. Monetary policy under alternative asset market structures: The case of a small open economy. Journal of Money, Credit and Banking, 41(7):1301-1330, October 2009.

[24] Kenneth Rogoff. Can international monetary policy cooperation be counterproductive? Journal of International Economics, 18(3-4):199-217, May 1985.

[25] Stephanie Schmitt-Grohé and Martín Uribe. The optimal rate of inflation. In Benjamin M. Friedman and Michael Woodford, editors, Handbook of Monetary Economics, volume 3 of Handbook of Monetary Economics, chapter 13, pages 653-722. Elsevier, 2010. 
[26] Alan Sutherland. International monetary policy coordination and financial market integration. CEPR Discussion Papers 4251, C.E.P.R. Discussion Papers, February 2004.

[27] Michael Woodford. Monetary policy in a world without money. International Finance, 3(2):229-60, July 2000. 


\section{A Appendix}

\section{A.1 Risk-sharing}

The household in country $i$ will maximize lifetime utility (1), subject to the following budget constraint and transversality condition:

$$
\begin{array}{r}
C_{i}\left(s_{t}\right) P_{i}\left(s_{t}\right)=W_{i}\left(s_{t}\right) N_{i}\left(s_{t}\right)+\int_{0}^{1} \mathcal{E}_{i j}\left(s_{t}\right) B_{i j}\left(s_{t}\right) d j \\
\sum_{t=1}^{\infty} \sum_{s_{t}} \int_{0}^{1} q_{j}\left(s_{t}\right) B_{i j}\left(s_{t}\right) d j=0 .
\end{array}
$$

$B_{i j}\left(s_{t}\right)$ denotes the state-contingent bond that pays in currency $j$ in state $s_{t} ; q_{j}\left(s_{t}\right)$ is the price of that bond in period 0 (when all trading occurs), $q_{j}\left(s_{t}\right)$ is arbitrary up to a constant. Household in period 0 cares about relative price of claims across states and currencies. The transverality condition stipulates that all period 0 transactions must be balanced: payment for claims issued must equal payment for claims received. The household Lagrangian is:

$$
\begin{aligned}
\mathcal{L}_{i}= & \sum_{t=1}^{\infty} \beta^{t} \operatorname{Pr}\left(s_{t}\right)\left\{U_{i}\left(C\left(s_{t}\right)\right)-V_{i}\left(N\left(s_{t}\right)\right)+\frac{\lambda_{i}\left(s_{t}\right)}{P_{i}\left(s_{t}\right)}\left[W_{i}\left(s_{t}\right) N_{i}\left(s_{t}\right)+\int_{0}^{1} \mathcal{E}_{i j} B_{i j}\left(s_{t}\right)\left(s_{t}\right) d j-C_{i}\left(s_{t}\right) P_{i}\left(s_{t}\right)\right]\right\} \\
& -\lambda_{i 0} \sum_{t=1}^{\infty} \sum_{s_{t}} \int_{0}^{1} q_{j}\left(s_{t}\right) B_{i j}\left(s_{t}\right) d j
\end{aligned}
$$

Now take the FOC with respect to state contingent bonds $B_{i j}\left(s_{t}\right)$ :

$$
\frac{\partial \mathcal{L}_{i}}{\partial B_{i j}\left(s_{t}\right)}=\lambda_{i 0} q_{j}\left(s_{t}\right)+\frac{\beta^{t} \lambda_{i}\left(s_{t}\right) \operatorname{Pr}\left(s_{t}\right) \mathcal{E}_{i j}\left(s_{t}\right)}{P_{i}\left(s_{t}\right)}=0
$$

which gives price of the state-contingent bond,

$$
q_{j}\left(s_{t}\right)=\beta^{t} \frac{\lambda_{i}\left(s_{t}\right) \operatorname{Pr}\left(s_{t}\right) \mathcal{E}_{i j}\left(s_{t}\right)}{\lambda_{i 0} P_{i}\left(s_{t}\right)}
$$

The analogous FOC for country $j, \frac{\partial \mathcal{L}_{j}}{\partial B_{j j}\left(s_{t}\right)}=0$ will yield:

$$
q_{j}\left(s_{t}\right)=\beta^{t} \frac{\lambda_{j}\left(s_{t}\right) \operatorname{Pr}\left(s_{t}\right) \mathcal{E}_{j j}\left(s_{t}\right)}{\lambda_{j 0} P_{j}\left(s_{t}\right)} .
$$

Using $\mathcal{E}_{j j}\left(s_{t}\right)=1$ and setting (A.5) equal to (A.6), we get the risk-sharing condition

$$
\frac{\lambda_{i}\left(s_{t}\right)}{\lambda_{j}\left(s_{t}\right)}=\frac{\lambda_{i 0}}{\lambda_{j 0}} \frac{P_{i}\left(s_{t}\right)}{P_{j}\left(s_{t}\right) \mathcal{E}_{i j}\left(s_{t}\right)} .
$$


When PPP holds, $\frac{P_{i}\left(s_{t}\right)}{P_{j}\left(s_{t}\right) \mathcal{E}_{i j}\left(s_{t}\right)}=1$, and the risk-sharing condition simplifies to $\frac{\lambda_{i}\left(s_{t}\right)}{\lambda_{j}\left(s_{t}\right)}=\left(\frac{C_{i}\left(s_{t}\right)}{C_{j}\left(s_{t}\right)}\right)^{-\sigma}=$ $\frac{\lambda_{i 0}}{\lambda_{j 0}}$. When the consumption ratio is constant across countries, $C_{i t}=A_{i} C_{w t}$.

In order to solve for $A_{i}$, we substitute (A.5) into the transversality condition.

$$
\begin{aligned}
\sum_{t=1}^{\infty} \sum_{s_{t}} \int_{0}^{1} q_{j}\left(s_{t}\right) B_{i j}\left(s_{t}\right) d j & =\sum_{t=1}^{\infty} \sum_{s_{t}} \int_{0}^{1} \beta^{t} \frac{\lambda_{i}\left(s_{t}\right) \operatorname{Pr}\left(s_{t}\right) \mathcal{E}_{i j}\left(s_{t}\right)}{\lambda_{i 0} P_{i}\left(s_{t}\right)} B_{i j}\left(s_{t}\right) d j \\
& =\sum_{t=1}^{\infty} \sum_{s_{t}} \beta^{t} \frac{\lambda_{i}\left(s_{t}\right) \operatorname{Pr}\left(s_{t}\right)}{\lambda_{i 0} P_{i}\left(s_{t}\right)} \int_{0}^{1} \mathcal{E}_{i j}\left(s_{t}\right) B_{i j}\left(s_{t}\right) d j \\
& \stackrel{(\mathrm{A} .1)}{=} \sum_{t=1}^{\infty} \sum_{s_{t}} \beta^{t} \frac{\lambda_{i}\left(s_{t}\right) \operatorname{Pr}\left(s_{t}\right)}{\lambda_{i 0} P_{i}\left(s_{t}\right)}\left(P_{i}\left(s_{t}\right) C_{i}\left(s_{t}\right)-W_{i}\left(s_{t}\right) N_{i}\left(s_{t}\right)\right) \\
& =0
\end{aligned}
$$

We substitute $C_{i}\left(s_{t}\right)=A_{i} C_{w}\left(s_{t}\right)$ into the above equation, and solve for $A_{i}$.

$$
\begin{aligned}
A_{i}= & \frac{\sum_{t=1}^{\infty} \sum_{s t} \beta^{t} \frac{W\left(s_{t}\right) N\left(s_{t}\right)}{P\left(s_{t}\right)} \lambda_{i}\left(s_{t}\right) \operatorname{Pr}\left(s_{t}\right)}{\sum_{t=1}^{\infty} \sum_{s_{t}} \beta^{t} C_{w}\left(s_{t}\right) \lambda_{i}\left(s_{t}\right) \operatorname{Pr}\left(s_{t}\right)} \\
= & \frac{\sum_{t=1}^{\infty} \beta^{t} \mathbb{E}_{t-1}\left\{\frac{W_{t} N_{t}}{P_{t}} \lambda_{i}\left(s_{t}\right)\right\}}{\sum_{t=1}^{\infty} \beta^{t} \mathbb{E}_{t-1}\left\{C_{w t} \lambda_{i}\left(s_{t}\right)\right\}} \\
= & \frac{\sum_{t=1}^{\infty} \beta^{t} \mathbb{E}_{t-1}\left\{Y_{i t}^{\frac{\gamma-1}{\gamma}} C_{w t}^{\frac{1}{\gamma}} \lambda_{i}\left(s_{t}\right)\right\}}{\sum_{t=1}^{\infty} \beta^{t} \mathbb{E}_{t-1}\left\{C_{w t} \lambda_{i}\left(s_{t}\right)\right\}} \\
= & \frac{\sum_{t=1}^{\infty} \beta^{t} \mathbb{E}_{t-1}\left\{Y_{i t}^{\frac{\gamma-1}{\gamma}} C_{w t}^{\frac{1}{\gamma}} C_{w t}^{-\sigma}\right\}}{\sum_{t=1}^{\infty} \beta^{t} \mathbb{E}_{t-1}\left\{C_{w t} C_{w t}^{-\sigma}\right\}}
\end{aligned}
$$

where we used $\lambda_{i}\left(s_{t}\right)=A_{i}^{-\sigma} C_{w}^{-\sigma}\left(s_{t}\right)$. This gives us the definition of complete markets from the text, equation (20).

\section{A.2 Closed Economy}

Proposition 2 In the closed economy under ex ante commitment, the central bank will maximize (24) subject to (25) and (26). The solution to this problem is: $C_{t}=\left(\frac{1-\tau}{\chi \mu}\right)^{\frac{1}{\sigma+\varphi}} Z_{t}^{\frac{1+\varphi}{\sigma+\varphi}}$. Price stability is the optimal policy, as the central bank exactly replicates the flexible price allocation.

Proof: The flexible price allocation is obtained from solving this two equation system in 
two unknowns $(C, N)$ :

$$
\begin{aligned}
& 1=\frac{\mu \chi}{1-\tau} \frac{N_{t}^{1+\varphi}}{C_{t}^{1-\sigma}}, \\
& C_{t}=Z_{t} N_{t} .
\end{aligned}
$$

The solution is $C_{t}=\left(\frac{1-\tau}{\mu \chi}\right)^{\frac{1}{\sigma+\varphi}} Z_{t}^{\frac{1+\varphi}{\sigma+\varphi}}$. Now, let's reformulate the central bank's problem by substituting the labor market clearing condition (25) and the goods market clearing condition (26) into the objective function.

$$
\max _{C_{t}} \mathbb{E}_{t-1}\left\{\frac{C_{t}^{1-\sigma}}{1-\sigma}-\chi \frac{C_{t}^{1+\varphi} Z_{t}^{-1-\varphi}}{(1+\varphi)}\right\}
$$

s.t.

$$
1=\frac{\mu \chi}{1-\tau} \frac{\mathbb{E}_{t-1}\left\{C_{t}^{1+\varphi} Z_{t}^{-(1+\varphi)}\right\}}{\mathbb{E}_{t-1} C_{t}^{1-\sigma}}
$$

The Lagrangian for this constrained optimization problem is

$$
\mathcal{L}=\mathbb{E}_{t-1}\left\{\frac{C_{t}^{1-\sigma}}{1-\sigma}-\chi \frac{C_{t}^{1+\varphi} Z_{t}^{-1-\varphi}}{(1+\varphi)}\right\}+\lambda\left(\mathbb{E}_{t-1} C_{t}^{1-\sigma}-\frac{\mu \chi}{1-\tau} \mathbb{E}_{t-1}\left\{C_{t}^{1+\varphi} Z_{t}^{-(1+\varphi)}\right\}\right)
$$

The first order condition with respect to consumption is ${ }^{15}$

$$
\frac{\partial \mathcal{L}}{\partial C_{t}}=(1+\lambda(1-\sigma)) C_{t}^{-\sigma}-\chi\left(1+\frac{\lambda \mu}{1-\tau}\right) C_{t}^{\varphi} Z_{t}^{-1-\varphi}=0
$$

which is equivalent to

$$
C_{t}^{1-\sigma}=\chi\left(\frac{1+\frac{\lambda \mu}{1-\tau}}{1+\lambda(1-\sigma)}\right) N_{t}^{1+\varphi}=0
$$

Given that $\lambda$ is a constant and not a variable, the first order condition and the budget constraint are satisfied only under the flexible price equilibrium. Thus, the central bank's optimal policy is to mimic the flexible price equilibrium in the closed economy.

Proposition 3 In the closed economy, the social planner will maximize (24) subject to (26), ignoring the labor condition (25). The solution to this problem is: $C_{t}=\left(\frac{1}{\chi}\right)^{\frac{1}{\sigma+\varphi}} Z_{t}^{\frac{1+\varphi}{\sigma+\varphi}}$. The social planner will replicate the flexible price allocation and remove the monopolistic markup, yielding the Pareto efficient allocation.

Proof: Insert the aggregate goods market clearing constraint (26) directly into the objective

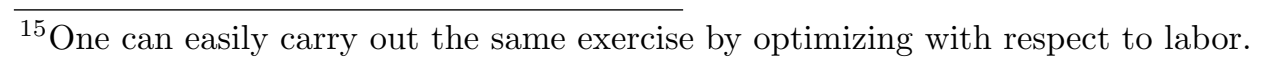


function, replacing $N_{t+1}$, and maximize this objective function.

$$
\max _{C_{t+1}}\left[\frac{C_{t+1}^{1-\sigma}}{1-\sigma}-\frac{\chi}{1+\varphi}\left(\frac{C_{t+1}}{Z_{t+1}}\right)^{1+\varphi}\right]
$$

The solution to this optimization problem is $C_{t}=\left(\frac{1}{\chi}\right)^{\frac{1}{\sigma+\varphi}} Z_{t}^{\frac{1+\varphi}{\sigma+\varphi}}$.

\section{A.3 Global Social Planner}

Proposition 4 The global social planner will maximize utility weighted over all $i$ countries (27), subject to (28) and (29). The solution to this optimization problem is:

$$
\begin{aligned}
& \mathbb{E}\left\{U_{i}\right\}=C_{i}^{1-\sigma}\left(\frac{1}{1-\sigma}-\frac{1}{1+\varphi}\right), \\
& C_{i}=\left(\frac{1}{\chi}\right)^{\frac{1}{\sigma+\varphi}} Z_{w}^{\frac{1+\varphi}{\sigma+\varphi}}, \\
& N_{i}=\left(\frac{1}{\chi}\right)^{\frac{1}{\sigma+\varphi}} Z_{w}^{\frac{(1-\gamma \sigma)(1+\varphi)}{(1+\gamma \varphi)(\sigma+\varphi)}} Z_{i}^{\frac{\gamma-1}{1+\gamma \varphi}}, \\
& Y_{i}=\left(\frac{1}{\chi}\right)^{\frac{1}{\sigma+\varphi}} Z_{w}^{\frac{(1-\gamma \sigma)(1+\varphi)}{(1+\gamma \varphi)(\sigma+\varphi)}} Z_{i}^{\frac{\gamma(1+\varphi)}{1+\gamma \varphi}}, \\
& Z_{w}=\left(\int_{0}^{1} Z_{i}^{\frac{(\gamma-1)(1+\varphi)}{1+\gamma \varphi}} d i\right)^{\frac{1+\gamma \varphi}{(\gamma-1)(1+\varphi)}} .
\end{aligned}
$$

The global social planner solution exactly replicates the flexible price allocation while eliminating monopolistic markups, yielding the Pareto optimal allocation.

Proof: If we substitute (28) and (29) directly into the objective function (27), then we can reformulate the problem as follows:

$$
\max _{\forall c_{i j}} \int_{0}^{1}\left[\frac{\left[\int_{0}^{1} c_{i j}^{\frac{\gamma-1}{\gamma}} d j\right]^{\frac{\gamma(1-\sigma)}{\gamma-1}}}{1-\sigma}-\frac{\chi}{1+\varphi}\left[\frac{\int_{0}^{1} c_{j i} d j}{Z_{i}}\right]^{1+\varphi}\right] d i
$$

Rearranging, we have

$$
\max _{c_{i j}} \frac{1}{1-\sigma} \int_{0}^{1}\left[\int_{0}^{1} c_{i j}^{\frac{\gamma-1}{\gamma}} d j\right]^{\frac{\gamma(1-\sigma)}{\gamma-1}} d i-\frac{\chi}{1+\varphi} \int_{0}^{1} \frac{\left[\int_{0}^{1} c_{j i} d j\right]^{1+\varphi}}{Z_{i}^{1+\varphi}} d i
$$


The FOC with respect to $c_{i j}$ is

$$
0=\left[\int_{0}^{1} c_{i j}^{\frac{\gamma-1}{\gamma}} d j\right]^{\frac{\gamma(1-\sigma)}{\gamma-1}-1} c_{i j}^{\frac{-1}{\gamma}}-\chi \frac{\left[\int_{0}^{1} c_{j i} d j\right]^{\varphi}}{Z_{j}^{1+\varphi}} .
$$

This is equivalent to

$$
\begin{aligned}
0 & =\underbrace{\left(\left[\int_{0}^{1} c_{i j}^{\frac{\gamma-1}{\gamma}} d j\right]^{\frac{1-\sigma \gamma}{\gamma-1}}\right)}_{=C_{i}^{\frac{1-\sigma \gamma}{\gamma}}} c_{i j}^{\frac{-1}{\gamma}}-\chi \underbrace{\left[\frac{\int_{0}^{1} c_{j i} d j}{Z_{j}}\right]^{\varphi}}_{=N_{j}^{\varphi}} \frac{1}{Z_{j}}, \\
\Rightarrow 0 & =C_{i}^{\frac{1-\sigma \gamma}{\gamma}} c_{i j}^{-\frac{1}{\gamma}}-\chi \frac{N_{j}^{\varphi}}{Z_{j}},
\end{aligned}
$$

and solving for $c_{i j}$ we have:

$$
c_{i j}=\frac{Z_{j}^{\gamma} C_{i}^{1-\gamma \sigma}}{\chi^{\gamma} N_{j}^{\gamma \varphi}} .
$$

The consumption basket in country $i\left(C_{i}\right)$ can then be expressed as:

$$
\begin{aligned}
C_{i} & =\left(\int_{0}^{1} c_{i j}^{\frac{\gamma-1}{\gamma}} d j\right)^{\frac{\gamma}{\gamma-1}}, \\
& =\left(\int_{0}^{1}\left[\frac{Z_{j}^{\gamma} C_{i}^{1-\gamma \sigma}}{\chi^{\gamma} N_{j}^{\gamma \varphi}}\right]^{\frac{\gamma-1}{\gamma}} d j\right)^{\frac{\gamma}{\gamma-1}}, \\
& =\left(\frac{1}{\chi}\right)^{\frac{1}{\sigma}}\left(\int_{0}^{1}\left[\frac{Z_{j}}{N_{j}^{\varphi}}\right]^{(\gamma-1)} d j\right)^{\frac{1}{\sigma(\gamma-1)}} .
\end{aligned}
$$

So $C_{i}$ does not depend on its own technology $Z_{i}$. Now, let's solve for labor $\left(N_{i}\right)$ and output $\left(Y_{i}\right)$.

$$
\begin{array}{rlr}
N_{i} & =\frac{Y_{i}}{Z_{i}} & \text { from goods market clearing } \\
& =\frac{\int_{0}^{1} c_{j i} d j}{Z_{i}} & \text { from }(29) \\
& =\frac{\int_{0}^{1}\left[\frac{Z_{i}^{\gamma} C_{j}^{1-\gamma \sigma}}{\chi^{\gamma} N_{i}^{\gamma \varphi}}\right] d j}{Z_{i}} & \text { from }(A .14) \\
& =\frac{Z_{i}^{\gamma-1}}{\chi^{\gamma} N_{i}^{\gamma \varphi}} \int_{0}^{1} C_{j}^{1-\gamma \sigma} d j &
\end{array}
$$


From (A.15), we know that $C_{i}=C_{j}=C$ for all $i, j$. So we can take $C_{j}$ outside of the integral in (A.16) and solve for $N_{i}$ :

$$
\begin{aligned}
N_{i} & =\frac{Z_{i}^{\gamma-1} C_{j}^{1-\gamma \sigma}}{\chi^{\gamma} N_{i}^{\gamma \varphi}} \\
\Rightarrow N_{i} & =\left(\frac{Z_{i}^{\gamma-1} C^{1-\gamma \sigma}}{\chi^{\gamma}}\right)^{\frac{1}{1+\gamma \varphi}} .
\end{aligned}
$$

Similarly, output will be:

$$
Y_{i}=\left(\frac{Z_{i}^{\gamma(1+\varphi)} C^{1-\gamma \sigma}}{\chi^{\gamma}}\right)^{\frac{1}{1+\gamma \varphi}} .
$$

Substitute (A.17) and (A.18) back into the definition of the consumption basket (A.15), and solve for the consumption basket $C$ in each country, which will be identical:

$$
\begin{aligned}
C & =\left(\frac{1}{\chi}\right)^{\frac{1}{\sigma}}\left[\int_{0}^{1}\left(\left(\frac{Z_{j}^{\gamma-1} C^{1-\gamma \sigma}}{\chi^{\gamma}}\right)^{\frac{1}{1+\gamma \varphi}}\right)^{-(\gamma-1) \varphi} Z_{j}^{\gamma-1} d j\right]^{\frac{1}{\sigma(\gamma-1)}}, \\
C^{\frac{\sigma+\varphi}{(1+\gamma \varphi) \sigma}} & =\left(\frac{1}{\chi}\right)^{\frac{1}{\sigma}}\left[\int_{0}^{1}\left(\frac{Z_{j}^{\gamma-1}}{\chi^{\gamma}}\right)^{-\frac{(\gamma-1) \varphi}{1+\gamma \varphi}} Z_{j}^{\gamma-1} d j\right]^{\frac{1}{\sigma(\gamma-1)}}, \\
\Rightarrow C & =C_{i}=\left(\frac{1}{\chi}\right)^{\frac{1}{\sigma+\varphi}}\left(\int_{0}^{1} Z_{j}^{\frac{(\gamma-1)(1+\varphi)}{1+\gamma \varphi}} d j\right)^{\frac{1+\gamma \varphi}{(\sigma+\varphi)(\gamma-1)}} .
\end{aligned}
$$

Solve for labor and output by substituting (A.19) into (A.17) and (A.18) respectively:

$$
\begin{aligned}
& N_{i}=\left(\frac{1}{\chi}\right)^{\frac{1}{\sigma+\varphi}}\left(\int_{0}^{1} Z_{j}^{\frac{(\gamma-1)(1+\varphi)}{1+\gamma \varphi}} d j\right)^{\frac{1-\gamma \sigma}{(\sigma+\varphi)(\gamma-1)}} Z_{i}^{\frac{\gamma-1}{1+\gamma \varphi}} \\
& Y_{i}=\left(\frac{1}{\chi}\right)^{\frac{1}{\sigma+\varphi}}\left(\int_{0}^{1} Z_{j}^{\frac{(\gamma-1)(1+\varphi)}{1+\gamma \varphi}} d j\right)^{\frac{1-\gamma \sigma}{(\sigma+\varphi)(\gamma-1)}} Z_{i}^{\frac{\gamma(1+\varphi)}{1+\gamma \varphi}}
\end{aligned}
$$

This is the Pareto efficient allocation. When $\gamma \rightarrow \infty$, the flexible price allocation and the global social planner allocation become identical. Consumption is identical to the first order between social planner and flexible price allocation. However, it is not true for labor.

\section{A.4 Complete Markets and Financial Autarky}

Proposition 5 In complete markets, non-cooperative central banks will maximize (30a) and cooperative central banks will maximize (30b), subject to (31), (32), (33) and (34). The solution under commitment for both cooperative and non-cooperative central banks in complete markets 
$i s:$

$$
\begin{aligned}
& \mathbb{E}\left\{U_{i}\right\}=C_{i}^{1-\sigma}\left(\frac{1}{1-\sigma}-\frac{1-\tau_{i}}{\mu(1+\varphi)}\right) \\
& C_{i}=\left(\frac{1-\tau_{i}}{\chi \mu}\right)^{\frac{1}{\sigma+\varphi}} Z_{w}^{\frac{1+\varphi}{\sigma+\varphi}} \\
& N_{i}=\left(\frac{1-\tau_{i}}{\chi \mu}\right)^{\frac{1}{\sigma+\varphi}} Z_{w}^{\frac{(1-\gamma \sigma)(1+\varphi)}{(1+\gamma \varphi)(\sigma+\varphi)}} Z_{i}^{\frac{\gamma-1}{1+\gamma \varphi}} \\
& Y_{i}=\left(\frac{1-\tau_{i}}{\chi \mu}\right)^{\frac{1}{\sigma+\varphi}} Z_{w}^{\frac{(1-\gamma \sigma)(1+\varphi)}{(1+\gamma)(\sigma+\varphi)}} Z_{i}^{\frac{\gamma(1+\varphi)}{1+\gamma \varphi}} \\
& Z_{w}=\left(\int_{0}^{1} Z_{i}^{\frac{(\gamma-1)(1+\varphi)}{1+\gamma \varphi}} d i\right)^{\frac{1+\gamma \varphi}{(\gamma-1)(1+\varphi)}}
\end{aligned}
$$

The resulting equilibrium allocation exactly coincides with the flexible price allocation. Mimicking the flexible price allocation is thus the dominant strategy for non-cooperative central banks in complete markets, and is the optimal policy under cooperation.

Proposition 6 In financial autarky, non-cooperative central banks will maximize (30a) and cooperative central banks will maximize (30b), subject to (35), (36), (37) and (38). The solution under commitment for both cooperative and non-cooperative central banks in financial autarky is:

$$
\begin{aligned}
& \mathbb{E}\left\{U_{i}\right\}=C_{i}\left(\frac{1}{1-\sigma}-\frac{1-\tau_{i}}{\mu(1+\varphi)}\right) \\
& C_{i}=\left(\frac{1-\tau_{i}}{\chi \mu}\right)^{\frac{1}{\sigma+\varphi}}\left(Z_{i}^{\gamma-1} Z_{w}^{\frac{1+\varphi}{\sigma+\varphi}}\right)^{\frac{1+\varphi}{1-\sigma+\gamma(\varphi+\sigma)}}, \\
& N_{i}=\left(\frac{1-\tau_{i}}{\chi \mu}\right)^{\frac{1}{\sigma+\varphi}}\left(Z_{i}^{\gamma-1} Z_{w}^{\frac{1+\varphi}{\sigma+\varphi}}\right)^{\frac{1-\sigma}{1-\sigma+\gamma(\varphi+\sigma)}}, \\
& Y_{i}=\left(\frac{1-\tau_{i}}{\chi \mu}\right)^{\frac{1}{\sigma+\varphi}}\left(Z_{i}^{\gamma-1} Z_{w}^{\frac{1+\varphi}{\sigma+\varphi}}\right)^{\frac{1-\sigma}{1-\sigma+\gamma(\varphi+\sigma)}} Z_{i}, \\
& Z_{w}=\left(\int_{0}^{1} Z_{i}^{\frac{(\gamma-1)(1+\varphi)}{1-\sigma+\gamma(\sigma+\varphi)}} d i\right)^{\frac{1-\sigma+\gamma(\sigma+\varphi)}{(\gamma-1)(1+\varphi)}} .
\end{aligned}
$$

The resulting equilibrium allocation exactly coincides with the flexible price allocation. Mimicking the flexible price allocation is thus the dominant strategy for non-cooperative central banks in financial autarky, and is the optimal policy under cooperation.

Proof: The objective function for non-cooperative and cooperative central banks will be, 
respectively:

$$
\begin{aligned}
& \max _{N_{i t}} \mathbb{E}_{t-1}\left\{\frac{C_{i t}^{1-\sigma}}{1-\sigma}-\chi \frac{N_{i t}^{1+\varphi}}{1+\varphi}\right\}, \\
& \max _{\forall N_{i t}} \int_{0}^{1}\left\{\frac{C_{i t}^{1-\sigma}}{1-\sigma}-\chi \frac{N_{i t}^{1+\varphi}}{1+\varphi}\right\} d i .
\end{aligned}
$$

Policymakers in each scenario will maximize their objective function subject to the following constraints:

$$
\begin{gathered}
1=\left(\frac{\chi \mu}{1-\tau_{i}}\right) \frac{\mathbb{E}_{t-1}\left\{N_{i t}^{1+\varphi}\right\}}{\mathbb{E}_{t-1}\left\{C_{i t}^{-\sigma} Y_{i t}^{\frac{\gamma-1}{\gamma}} C_{w t}^{\frac{1}{\gamma}}\right\}}, \\
Y_{i t}=Z_{i t} N_{i t}, \\
C_{w t}=\left(\int_{0}^{1} Y_{i t}^{\frac{\gamma-1}{\gamma}}\right)^{\frac{\gamma}{\gamma-1}} \cdot \\
C_{i t}=C_{w t}^{\frac{1}{\gamma}} \mathbb{E}_{t-1}\left\{Y_{i t}^{\frac{\gamma-1}{\gamma}}\right\} \\
C_{i t}=C_{w t}^{\frac{1}{\gamma}} Y_{i t}^{\frac{\gamma-1}{\gamma}}
\end{gathered}
$$

where (A.26a) refers to goods market clearing under complete markets, while (A.26b) refers to goods market clearing under financial autarky. We can formulate a Lagrangian for the non-cooperative and cooperative cases:

$$
\begin{aligned}
& \mathcal{L}=\frac{\mathbb{E}_{t-1}\left\{C_{i t}^{1-\sigma}\right\}}{1-\sigma}-\chi \frac{\mathbb{E}_{t-1}\left\{N_{i t}^{1+\varphi}\right\}}{1+\varphi}+\lambda_{i}\left(\mathbb{E}_{t-1}\left\{C_{i t}^{1-\sigma}\right\}-\frac{\chi \mu}{1-\tau_{i}} \mathbb{E}_{t-1}\left\{N_{i t}^{1+\varphi}\right\}\right) \\
& \mathcal{L}=\int_{0}^{1}\left[\frac{\mathbb{E}_{t-1}\left\{C_{i t}^{1-\sigma}\right\}}{1-\sigma}-\chi \frac{\mathbb{E}_{t-1}\left\{N_{i t}^{1+\varphi}\right\}}{1+\varphi}+\lambda_{i}\left(\mathbb{E}_{t-1}\left\{C_{i t}^{1-\sigma}\right\}-\frac{\chi \mu}{1-\tau_{i}} \mathbb{E}_{t-1}\left\{N_{i t}^{1+\varphi}\right\}\right)\right] d i
\end{aligned}
$$

Using $C_{i t}=C_{w t}^{\frac{1}{\gamma}} \mathbb{E}_{t-1}\left\{N_{i t}^{\frac{\gamma-1}{\gamma}} Z_{i t}^{\frac{\gamma-1}{\gamma}}\right\}$ for complete markets, or $C_{i t}=C_{w t}^{\frac{1}{\gamma}} N_{i t}^{\frac{\gamma-1}{\gamma}} Z_{i t}^{\frac{\gamma-1}{\gamma}}$ for financial autarky, we can take the first order condition with respect to $N_{i t} .{ }^{16}$ The FOC will be identical

\footnotetext{
${ }^{16}$ Remember that we are optimizing given the fact that state $s_{t}$ is realized. Expectations in our context thus refer to a summation over all possible states multiplied by the probability of each state occuring. For example, $\mathbb{E}_{t-1}\left\{C_{i t}^{1-\sigma}\right\}=\sum_{s_{t}} C_{i}^{1-\sigma}\left(s_{t}\right) \operatorname{Pr}\left(s_{t}\right)$.
} 
in both cases.

$$
\frac{\partial \mathcal{L}}{\partial N_{i t}}=C_{i t}^{-\sigma}\left(1+\lambda_{i}(1-\sigma)\right)\left(\frac{\gamma-1}{\gamma}\right)\left(\frac{Y_{i t}^{\frac{\gamma-1}{\gamma}} C_{w t}^{\frac{1}{\gamma}}}{N_{i t}}\right)-\chi\left(1+\lambda \frac{\mu}{1-\tau_{i}}(1+\varphi)\right) \frac{1}{N_{i t}} N_{i t}^{1+\varphi}=0
$$

In equilibrium, this equals:

$$
1=\underbrace{\chi\left(\frac{1+\frac{\lambda_{i} \mu(1+\varphi)}{1-\tau_{i}}}{1+\frac{\lambda_{i}(1-\sigma)(\gamma-1)}{\gamma}}\right)}_{\text {Constant }}\left(\frac{N_{i t}^{1+\varphi}}{C_{i t}^{-\sigma} Y_{i t}^{\frac{\gamma-1}{\gamma}} C_{w t}^{\frac{1}{\gamma}}}\right) .
$$

This equation holds in both complete markets and financial autarky, and differs from the flexible price equilibrium only by the constant term. However, subject to labor market clearing, this constant will coincide with the flexible price equilibrium. The flexible price equilibrium in complete markets and financial autarky is found by taking expectations out of the labor market clearing condition (A.23) and substituting in goods market clearing (A.24):

$$
1=\left(\frac{\chi \mu}{1-\tau_{i}}\right) \frac{Y_{i t}^{\frac{1+\varphi \gamma}{\gamma}}}{C_{i t}^{-\sigma} C_{w t}^{\frac{1}{\gamma}} Z_{i t}^{1+\varphi}}
$$

For complete markets, we can express output as a function of technology and a constant term by substituting (A.26a) into (A.30): $Y_{i t}=A_{i} Z_{i t}^{\frac{\gamma(1+\varphi)}{1+\gamma \varphi}}$. (We can do the same for exercise for autarky by substituting (A.26b) into (A.30), but leave that to the reader). Using this expression for output, consumption in complete markets in country $i$ can be expressed as

$$
C_{i t}=A_{i}^{\frac{\gamma-1}{\gamma}} C_{w t}^{\frac{1}{\gamma}} \mathbb{E}_{t-1}\left\{Z_{i t}^{\frac{(\gamma-1)(1+\varphi)}{1+\gamma \varphi}}\right\}
$$

Now substitute (A.31) back into the flexible price equilibrium (A.30)

$$
1=\left(\frac{\chi \mu}{1-\tau_{i}}\right) C_{w t}^{\frac{\sigma}{\gamma}} A_{i}^{\frac{(\gamma-1) \sigma}{\gamma}} \mathbb{E}_{t-1}\left\{Z_{i t}^{\frac{(\gamma-1)(1+\varphi)}{1+\gamma \varphi}}\right\}^{\sigma} A_{i}^{\frac{1+\varphi \gamma}{\gamma}} C_{w t}^{-\frac{1}{\gamma}}
$$

and rearrange and solve for $A_{i}$ :

$$
A_{i}=\left[\left(\frac{1-\tau_{i}}{\chi \mu}\right)^{\gamma} C_{w t}^{1-\sigma} \mathbb{E}_{t-1}\left\{Z_{i t}^{\frac{(\gamma-1)(1+\varphi)}{1+\gamma \varphi}}\right\}^{-\sigma \gamma}\right]^{\frac{1}{1-\sigma+\gamma(\varphi+\sigma)}}
$$


Now, substitute the solution for $A_{i},($ A.33), into (A.31):

$$
C_{i t}=\left[\left(\frac{\chi \mu}{1-\tau_{i}}\right)^{1-\gamma} C_{w t}^{\varphi+1} \mathbb{E}_{t-1}\left\{Z_{i t}^{\frac{(\gamma-1)(1+\varphi)}{1+\gamma \varphi}}\right\}^{1+\gamma \varphi}\right]^{\frac{1}{1-\sigma+\gamma(\varphi+\sigma)}}
$$

Using the fact that $C_{w t}=\int_{0}^{1} C_{i t} d i$ and setting $Z_{w}=\left(\int_{0}^{1} Z_{i}^{\frac{(\gamma-1)(1+\varphi)}{1+\gamma \varphi}} d i\right)^{\frac{1+\gamma \varphi}{(\gamma-1)(1+\varphi)}}$, consumption for country $i$ in complete markets is:

$$
C_{i t}=\left(\frac{1-\tau_{i}}{\chi \mu}\right)^{\frac{1}{\sigma+\varphi}} Z_{w}^{\frac{1+\varphi}{\sigma+\varphi}}
$$

Solving for labor and output using (A.35) is a straightforward exercise. The solution to the central bank's problem in complete markets and financial autarky for cooperative and noncooperative equilibria, coincides exactly with the flexible price allocation. Here we've explicitly outlined the proof for complete markets. The proof for financial autarky is identical up to (A.30). We simply substitute (A.26b) into (A.30) to get the optimal allocation under financial autarky.

\section{B Local Currency Pricing}

Proposition 7 Under LCP, non-cooperative central banks will maximize (30a) subject to (39) and (40). A fixed exchange rate will be the Nash equilibrium policy for a non-cooperative central bank in both complete markets and financial autarky under LCP.

\section{Proof:}

In this section we explain the case of LCP in the continuum framework. First, let another country $j$ import goods from firm $h$ in country $i$.

\section{B.1 Price Setting}

Profits from the exports of firm $h$ in country $i$ to country $j$ in domestic currency will be:

$$
P_{j i t}(h) \mathcal{E}_{i j t} C_{j i t}(h)-W_{i t} N_{j i t}(h)
$$

where $P_{j i t}(h)$ denotes the price charged by firm $h$ in country $j$ which is located in country $i$. This price will be denominated in currency $j . N_{j i t}(h)$ is the amount of labor used by firm $h$ (which is manufacturing in country $i$ ) in the production of its exports to country $j$. Given this, firm $h$ will choose the price that maximizes its expected profit:

$$
\mathbb{E}_{t-1}\left\{C_{i t}^{-\sigma}\left(\frac{P_{j i t}(h) \mathcal{E}_{i j t} C_{j i t}(h)-W_{i t} N_{j i t}(h)}{C P I_{i t}}\right)\right\}
$$


We also have demand for firm $h$ 's good:

$$
C_{j i t}(h)=\left(\frac{P_{j i t}(h)}{P_{j i t}}\right)^{-\varepsilon} C_{j i t}
$$

In order to solve the maximization problem, we substitute the demand for firm $h$ 's good (B.3) into the expected profit function (B.2) and take the FOC with respect to $P_{j i t}(h)$. The FOC will be:

$$
\mathbb{E}_{t-1}\left\{C_{i t}^{-\sigma}\left(\frac{P_{j i t}(h) \mathcal{E}_{i j t} C_{j i t}(h)}{P_{j i t}(h) C P I_{i t}}\right)\right\}=\frac{\varepsilon}{\varepsilon-1} \mathbb{E}_{t-1}\left\{\frac{W_{i t} N_{j i t}(h)}{P_{j i t}(h) C P I_{i t}}\right\}
$$

$P_{j i t}(h)$ on the LHS will cancel out, and we will be left with:

$$
\mathbb{E}_{t-1}\left\{C_{i t}^{-\sigma} \frac{\mathcal{E}_{i j t} C_{j i t}(h)}{C P I_{i t}}\right\}=\mu \mathbb{E}_{t-1}\left\{C_{i t}^{-\sigma} \frac{W_{i t} N_{j i t}(h)}{P_{j i t}(h) C P I_{i t}}\right\}
$$

\section{B.2 Labor Market Clearing}

We can take out the $h$ index for firms because they are all identical. Now, substituting labor supply $\frac{\chi}{1-\tau_{i}} \frac{W_{i t}}{C P I_{i t}}=N_{i t}^{\varphi} C_{i t}^{\sigma}$ into the above equation, we get

$$
\mathbb{E}_{t-1}\left\{C_{i t}^{-\sigma} \frac{\mathcal{E}_{i j t} C_{j i t}}{C P I_{i t}}\right\}=\frac{\chi \mu}{1-\tau_{i}} \mathbb{E}_{t-1}\left\{\frac{N_{i t}^{\varphi} N_{j i t}}{P_{j i t}}\right\}
$$

Substituting the identities $N_{j i t}=C_{j i t} Z_{i t}^{-1}$ and $C_{j i t}=\left(\frac{P_{j i t}}{C P I_{j t}}\right)^{-\gamma} C_{j t}$ into the above equation gives:

$$
\mathbb{E}_{t-1}\left\{C_{i t}^{-\sigma} \frac{\mathcal{E}_{i j t} P_{j i t}^{-\gamma} C P I_{j t}^{\gamma} C_{j i t}}{C P I_{i t}}\right\}=\frac{\chi \mu}{1-\tau_{i}} \mathbb{E}_{t-1}\left\{\frac{N_{i t}^{\varphi} P_{j i t}^{-\gamma} C P I_{j t}^{\gamma} C_{j i t}}{Z_{i t} P_{j i t}}\right\} .
$$

Now we use the fact that $C P I_{i t}, P_{j i t}$ and $N_{i t}$ are predetermined:

$$
\mathbb{E}_{t-1}\left\{C_{i t}^{-\sigma} \frac{\mathcal{E}_{i j t} Y_{i t} P_{j i t} C_{j t}}{C P I_{i t}}\right\}=\frac{\chi \mu}{1-\tau_{i}} \mathbb{E}_{t-1}\left\{N_{i t}^{1+\varphi} C_{j t}\right\}
$$

The next step in our derivation requires that we assume there is a common numeraire country, call it 0 , and all countries fix their currency with respect to this numeraire currency. This means that $\mathcal{E}_{i j t}=\mathcal{E}_{i 0 t} \mathcal{E}_{0 j t}$. When combined with predetermined prices and output, the following condition emerges:

$$
\mathbb{E}_{t-1}\left\{C_{i t}^{-\sigma} \frac{Y_{i t} P_{j i t}}{C P I_{i t}} \mathcal{E}_{i 0 t}\right\}=\frac{\chi \mu}{1-\tau_{i}} \frac{\mathbb{E}_{t-1}\left\{C_{j t}\right\} \mathbb{E}_{t-1}\left\{N_{i t}^{1+\varphi}\right\}}{\mathbb{E}_{t-1}\left\{\mathcal{E}_{0 j t} C_{j t}\right\}}
$$




\section{B.3 Nash Equilibrium}

Here we assume that all countries, with the expection of country $i$, have a fixed exchange rate with the numeraire currency, such that $\mathcal{E}_{0 j t}=1$. Given this assumption, the labor clearing condition becomes

$$
\mathbb{E}_{t-1}\left\{C_{i t}^{-\sigma} \frac{Y_{i t} P_{j i t}}{C P I_{i t}} \mathcal{E}_{i 0 t}\right\}=\frac{\chi \mu}{1-\tau_{i}} \mathbb{E}_{t-1}\left\{N_{i t}^{1+\varphi}\right\}
$$

Let us now write out the same equation for the numeraire country exporting to $i$ and $j$ respectively:

$$
\begin{array}{r}
\mathbb{E}_{t-1}\left\{C_{0 t}^{-\sigma} \frac{Y_{0 t} P_{i 0 t}}{C P I_{0 t}} \mathcal{E}_{00 t}\right\}=\frac{\chi \mu}{1-\tau_{0}} \mathbb{E}_{t-1}\left\{N_{0 t}^{1+\varphi}\right\} \frac{\mathbb{E}_{t-1} C_{i t}}{\mathbb{E}_{t-1}\left[\mathcal{E}_{0 i t} C_{i t}\right]}, \\
\mathbb{E}_{t-1}\left\{C_{0 t}^{-\sigma} \frac{Y_{0 t} P_{j 0 t}}{C P I_{0 t}} \mathcal{E}_{00 t}\right\}=\frac{\chi \mu}{1-\tau_{0}} \mathbb{E}_{t-1}\left\{N_{0 t}^{1+\varphi}\right\} \frac{\mathbb{E}_{t-1} C_{j t}}{\mathbb{E}_{t-1}\left[\mathcal{E}_{0 j t} C_{j t}\right]} .
\end{array}
$$

If we divide (B.11) by (B.12), and use the fact that prices are predetermined and $\mathcal{E}_{0 j t}=1$, we get

$$
\frac{P_{i 0 t}}{P_{j 0 t}}=\frac{C P I_{i t}}{C P I_{j t}}=\frac{C P I_{i t}}{C P I_{0 t}}=\frac{\mathbb{E}_{t-1} C_{i t}}{\mathbb{E}_{t-1}\left[\mathcal{E}_{0 i t} C_{i t}\right]} .
$$

\section{B.4 Financial Autarky}

In autarky, we assume all economies in the rest of the world $(-i)$ are ex-ante identical and that the actions of country $i$ will not influence their policy decisions. Therefore, prices and price indices will be equalized across all $-i$ countries, so that $P_{0 i t}=P_{j i t}$ and $C P I_{0 t}=C P I_{j t}$ respectively. This will lead to the following set of identities:

$$
C_{i t}=\frac{\int_{0}^{1} C_{j i t} P_{0 i t} \mathcal{E}_{i j t} d j}{C P I_{i t}}=\frac{P_{0 i t}}{C P I_{i t}} \int_{0}^{1} C_{j i t} \mathcal{E}_{i j t} d j=\frac{P_{0 i t}}{C P I_{i t}} \mathcal{E}_{i 0 t} \int_{0}^{1} C_{j i t} \mathcal{E}_{0 j t} d j=\frac{P_{0 i t}}{C P I_{i t}} \mathcal{E}_{i 0 t} Y_{i t}
$$

Output is standard:

$$
\begin{aligned}
Y_{i t} & =\int_{0}^{1} C_{j i t} d j=\int_{0}^{1}\left(\frac{P_{j i t}}{C P I_{j t}}\right)^{-\gamma} C_{j t} d j=\left(\frac{P_{0 i t}}{C P I_{0 t}}\right)^{-\gamma} C_{w t}, \\
\frac{P_{0 i t}}{C P I_{0 t}} & =Y_{i t}^{\frac{-1}{\gamma}} C_{w t}^{\frac{1}{\gamma}} .
\end{aligned}
$$

Now we can plug these equations into the labor market clearing equation (39).

$$
\mathbb{E}_{t-1} C_{i t}^{1-\sigma}=\frac{\chi \mu}{1-\tau_{i}} \mathbb{E}_{t-1} N_{i t}^{1+\varphi}
$$


Goods market clearing will be the following

$$
C_{i t}=\frac{P_{0 i t}}{C P I_{i t}} \mathcal{E}_{i 0 t} Y_{i t}=\frac{P_{0 i t}}{C P I_{0 t}} \frac{C P I_{0 t}}{C P I_{i t}} \mathcal{E}_{i 0 t} Y_{i t}=\frac{\mathcal{E}_{i 0 t} C P I_{0 t}}{C P I_{i t}} Y_{i t}^{\frac{\gamma-1}{\gamma}} C_{w t}^{\frac{1}{\gamma}} \text {. }
$$

Using (B.13), this can be rewritten as:

$$
C_{i t}=\frac{\mathbb{E}_{t-1}\left\{\mathcal{E}_{0 i t} C_{i t}\right\}}{\mathcal{E}_{0 i t} \mathbb{E}_{t-1}\left\{C_{i t}\right\}} Y_{i t}^{\frac{\gamma-1}{\gamma}} C_{w t}^{\frac{1}{\gamma}}
$$

The optimization problem of the non-cooperative central bank in country $i$ will then be:

$$
\begin{aligned}
\mathcal{L}= & \mathbb{E}_{t-1}\left\{C_{i t}^{1-\sigma}\right\}-\chi Y_{i t}^{1+\varphi} \mathbb{E}_{t-1}\left\{Z_{i t}^{-1-\varphi}\right\}+\lambda_{1}\left[\mathbb{E}_{t-1} C_{i t}^{1-\sigma}-\frac{\chi \mu}{1-\tau_{i}} \mathbb{E}_{t-1} N_{i t}^{1+\varphi}\right] \\
& +\lambda_{2}\left[C_{i t}-\frac{\mathbb{E}_{t-1}\left[\mathcal{E}_{0 i t} C_{i t}\right]}{\mathcal{E}_{0 i t} \mathbb{E}_{t-1} C_{i t}} Y_{i t}^{\frac{\gamma-1}{\gamma}} C_{w t}^{\frac{1}{\gamma}}\right]
\end{aligned}
$$

Maximization with respect to $\mathcal{E}_{0 i t}$ will yield the following FOC:

$$
\begin{aligned}
\frac{\partial \mathcal{L}}{\partial \mathcal{E}_{0 i t}} & =-\frac{1}{\mathcal{E}_{0 i t}} Y_{i t}^{\frac{\gamma-1}{\gamma}} C_{w t}^{\frac{1}{\gamma}}+\frac{\mathbb{E}_{t-1}\left[\mathcal{E}_{0 i t} C_{i t}\right]}{\mathcal{E}_{0 i t}^{2} \mathbb{E}_{t-1} C_{i t}} Y_{i t}^{\frac{\gamma-1}{\gamma}} C_{w t}^{\frac{1}{\gamma}}=0 \\
\Rightarrow \mathbb{E}_{t-1}\left\{\mathcal{E}_{0 i t} C_{i t}\right\} & =\mathcal{E}_{0 i t} \mathbb{E}_{t-1}\left\{C_{i t}\right\}
\end{aligned}
$$

This proves that the optimal exchange rate chosen by the central bank must not be statecontingent. In other words, the central bank will choose to fix its exchange rate.

\section{B.5 Complete Markets}

In this section, we assume that the degree of exchange rate pass-through is governed by parameter $\eta \in[0,1]$, where $\eta=1$ is perfect pass-through (PCP) and $\eta=0$ is zero pass-through (LCP). Maximization of (A.3) with respect to state contingent bonds yields the following FOC:

$$
\frac{\lambda_{i}\left(s_{t}\right)}{\lambda_{j}\left(s_{t}\right)}=\frac{\lambda_{i 0}}{\lambda_{j 0}} \frac{P_{i}\left(s_{t}\right)}{P_{j}\left(s_{t}\right) \mathcal{E}_{i j}\left(s_{t}\right)}=\frac{\lambda_{i 0}}{\lambda_{j 0}} \frac{\mathcal{E}_{i 0 t}^{\eta}\left(s_{t}\right)}{\mathcal{E}_{j 0 t}^{\eta}\left(s_{t}\right) \mathcal{E}_{i j}\left(s_{t}\right)}=\frac{\lambda_{i 0}}{\lambda_{j 0}} \mathcal{E}_{i j t}^{\eta-1}
$$

Using marginal utility, this will become:

$$
\frac{C_{i t}^{-\sigma}}{C_{j t}^{-\sigma}}=\mathcal{E}_{i j t}^{\eta-1}
$$

So we can express consumption in the following way: $C_{i t}=A_{i} \mathcal{E}_{i j t}^{\frac{1-\eta}{\sigma}} C_{j t}$. Using the fact that $C_{j t}=C_{w t}$, this will become $C_{i t}=A_{i} \mathcal{E}_{i 0 t}^{\frac{1-\eta}{\sigma}} C_{w t}$. To find $A_{i}$ we plug this expression into the 
transversality condition.

$$
\begin{aligned}
\sum_{t=1}^{\infty} \sum_{s_{t}} \int_{0}^{1} q_{j}\left(s_{t}\right) B_{i j}\left(s_{t}\right) d j & =\sum_{t=1}^{\infty} \sum_{s_{t}} \int_{0}^{1} \beta^{t} \frac{\lambda_{i}\left(s_{t}\right) \operatorname{Pr}\left(s_{t}\right) \mathcal{E}_{i j}\left(s_{t}\right)}{\lambda_{i 0} P_{i}\left(s_{t}\right)} B_{i j}\left(s_{t}\right) d j \\
& =\sum_{t=1}^{\infty} \sum_{s_{t}} \beta^{t} \frac{\lambda_{i}\left(s_{t}\right) \operatorname{Pr}\left(s_{t}\right)}{\lambda_{i 0} P_{i}\left(s_{t}\right)} \int_{0}^{1} \mathcal{E}_{i j}\left(s_{t}\right) B_{i j}\left(s_{t}\right) d j \\
& \stackrel{(\text { A.1) }}{=} \sum_{t=1}^{\infty} \sum_{s_{t}} \beta^{t} \frac{\lambda_{i}\left(s_{t}\right) \operatorname{Pr}\left(s_{t}\right)}{\lambda_{i 0} P_{i}\left(s_{t}\right)}\left(P_{i}\left(s_{t}\right) C_{i}\left(s_{t}\right)-W_{i}\left(s_{t}\right) N_{i}\left(s_{t}\right)-\Pi_{i}\left(s_{t}\right)\right) \\
= & 0 \\
A_{i}= & \frac{\sum_{t=0}^{\infty} \sum_{s t} \beta^{t} \frac{W\left(s_{t}\right) N\left(s_{t}\right)}{P\left(s_{t}\right)} \lambda_{i}\left(s_{t}\right) \operatorname{Pr}\left(s_{t}\right)}{\sum_{t=0}^{\infty} \sum_{s_{t}} \beta^{t} \mathcal{E}_{i 0 t}^{\frac{1-\eta}{\sigma}} C_{w}\left(s_{t}\right) \lambda_{i}\left(s_{t}\right) \operatorname{Pr}\left(s_{t}\right)} \\
= & \frac{\sum_{t=0}^{\infty} \beta^{t} \mathbb{E}_{t}\left\{\frac{W_{t} N_{t}}{P_{t}} \lambda_{i}\left(s_{t}\right)\right\}}{\sum_{t=0}^{\infty} \beta^{t} \mathbb{E}_{t-1}\left\{\mathcal{E}_{i 0 t}^{\frac{1-\eta}{\sigma}} C_{w t} \lambda_{i}\left(s_{t}\right)\right\}} \\
= & \frac{\sum_{t=0}^{\infty} \beta^{t} \mathbb{E}_{t}\left\{Y_{i t} T O T_{i t} \lambda_{i}\left(s_{t}\right)\right\}}{\sum_{t=0}^{\infty} \beta^{t} \mathbb{E}_{t}\left\{\mathcal{E}_{i 0 t}^{\frac{1-\eta}{\sigma}} C_{w t} \lambda_{i}\left(s_{t}\right)\right\}} \\
= & \frac{\sum_{t=0}^{\infty} \beta^{t} \mathbb{E}_{t}\left\{Y_{i t} T O T_{i t} C_{w t}^{-\sigma}\right\}}{\sum_{t=0}^{\infty} \beta^{t} \mathbb{E}_{t}\left\{\mathcal{E}_{i 0 t}^{\frac{1-\eta}{\sigma}} C_{w t} C_{w t}^{-\sigma}\right\}} \\
& \\
& \\
&
\end{aligned}
$$

Given the solution for $A_{i}$, it follows that:

$$
C_{i t}=\frac{\sum_{t=0}^{\infty} \beta^{t} \mathbb{E}_{0}\left\{Y_{i t} T O T_{i t} C_{w t}^{-\sigma}\right\}}{\sum_{t=0}^{\infty} \beta^{t} \mathbb{E}_{0}\left\{\mathcal{E}_{i 0 t}^{\frac{1-\eta}{\sigma}} C_{w t}^{1-\sigma}\right\}} \mathcal{E}_{i 0 t}^{\frac{1-\eta}{\sigma}} C_{w t}
$$

If technology shocks are independent across time, then $C_{i t}=\frac{\mathbb{E}_{t-1}\left\{Y_{i t} T O T_{i t} C_{w t}^{-\sigma}\right\}}{\mathbb{E}_{t-1}\left\{\mathcal{E}_{i 0 t}^{\frac{1-\eta}{\sigma}} C_{w t}^{1-\sigma}\right\}} \mathcal{E}_{i 0 t}^{\frac{1-\eta}{\sigma}} C_{w t}$. Assuming independence of shocks across countries as well, we obtain $C_{i t}=\frac{\mathbb{E}_{t-1}\left\{Y_{i t} T O T_{i t}\right\}}{\mathbb{E}_{t-1}\left\{\mathcal{E}_{i 0 t}^{\frac{1-\eta}{\sigma}}\right\}} \mathcal{E}_{i 0 t}^{\frac{1-\eta}{\sigma}}$. 
Under LCP, if all countries except $i$ have a fixed exchange rate, we have

$$
\begin{aligned}
C_{i t} & =\mathbb{E}_{t-1}\left\{\frac{\int_{0}^{1} C_{j i t} P_{0 i t} \mathcal{E}_{i j t} d j}{C P I_{i t}}\right\} \frac{\mathcal{E}_{i 0 t}^{\frac{1}{\sigma}}}{\mathbb{E}_{t-1}\left\{\mathcal{E}_{i 0 t}^{\frac{1}{\sigma}}\right\}} \\
& =\mathbb{E}_{t-1}\left\{\frac{P_{0 i t}}{C P I_{i t}} \mathcal{E}_{i 0 t} \int_{0}^{1} C_{j i t} \mathcal{E}_{0 j t} d j\right\} \frac{\mathcal{E}_{i 0 t}^{\frac{1}{\sigma}}}{\mathbb{E}_{t-1}\left\{\mathcal{E}_{i 0 t}^{\frac{1}{\sigma}}\right\}} \\
& =\mathbb{E}_{t-1}\left\{\frac{P_{0 i t}}{C P I_{i t}} \mathcal{E}_{i 0 t} Y_{i t}\right\} \frac{\mathcal{E}_{i 0 t}^{\frac{1}{\sigma}}}{\mathbb{E}_{t-1}\left[\mathcal{E}_{i 0 t}^{\frac{1}{\sigma}}\right]}
\end{aligned}
$$

Now we assume $\sigma=1$, so that we have log utility. The goods market clearing constraint in complete markets will then be:

$$
C_{i t}=\frac{P_{0 i t}}{C P I_{i t}} \mathcal{E}_{i 0 t} Y_{i t}
$$

Notice that this expression is identical to (40), the goods market clearing constraint in financial autarky. Since the labor equilibrium condition is also identical to the labor equilibrium condition in autarky, and the objective function does not change, the solution to the central bank's optimization problem in complete markets will be identical to that in autarky.

Proposition 8 Under LCP, cooperative central banks will maximize (30b) subject to (41) and (42). The optimal policy for cooperative central banks in both complete markets and financial autarky will be a fixed exchange rate.

\section{Proof:}

\section{B.6 Financial Autarky}

$$
C_{i t}=\frac{\int_{0}^{1} C_{j i t} P_{j i t} \mathcal{E}_{i j t} d j}{C P I_{i t}}
$$

Now we assume $\sigma=1$, and $P_{j i t}=P_{0 i t}=C P I_{0 t}=C P I_{i t}$ because of ex-ante symmetry, so the above equation becomes:

$$
C_{i t}=\mathcal{E}_{i 0 t} \int_{0}^{1} C_{j i t} \mathcal{E}_{0 j t} d j
$$

\section{B.7 Complete Markets}

$$
C_{i t}=\mathbb{E}_{t-1}\left\{\frac{\int_{0}^{1} C_{j i t} P_{0 i t} \mathcal{E}_{i j t} d j}{C P I_{i t}}\right\} \frac{\mathcal{E}_{i 0 t}^{\frac{1}{\sigma}}}{\mathbb{E}_{t-1}\left\{\mathcal{E}_{i 0 t}^{\frac{1}{\sigma}}\right\}}=\mathbb{E}_{t-1}\left\{\frac{P_{0 i t}}{C P I_{i t}} \mathcal{E}_{i 0 t} \int_{0}^{1} C_{j i t} \mathcal{E}_{0 j t} d j\right\} \frac{\mathcal{E}_{i 0 t}^{\frac{1}{\sigma}}}{\mathbb{E}_{t-1}\left\{\mathcal{E}_{i 0 t}^{\frac{1}{\sigma}}\right\}}
$$


Again, we assume $\sigma=1$, and $P_{j i t}=P_{0 i t}=C P I_{0 t}=C P I_{i t}$ because of ex-ante symmetry, so the above equation becomes:

$$
C_{i t}=\mathcal{E}_{i 0 t} \int_{0}^{1} C_{j i t} \mathcal{E}_{0 j t} d j
$$

Notice that this expression is identical to autarky. Since the labor equilibrium condition is also identical to autarky, the optimization problem for cooperative central banks under LCP will be identical in complete markets and autarky.

We know that output will be predetermined because prices are predetermined. As a result, exchange rate policy can affect only consumption, but not labor. Therefore the maximization problem faced by cooperative central banks will be as follows:

$$
\mathcal{L}=\int_{0}^{1} C_{i t}^{1-\sigma} d i=\int_{0}^{1} C_{i t}^{1-\sigma} d i+\int_{0}^{1} \lambda_{i t}\left(C_{i t}-\mathcal{E}_{i 0 t} \int_{0}^{1} C_{j t} \mathcal{E}_{j 0 t}^{-1} d j\right) d i
$$

The FOC with respect to $\mathcal{E}_{i 0 t}$ is

$$
\frac{\partial \mathcal{L}}{\partial \mathcal{E}_{i 0 t}}=-\lambda_{i t} \frac{C_{i t}}{\mathcal{E}_{i 0 t}}+\int_{0}^{1} \lambda_{j t} \mathcal{E}_{j 0 t} C_{i t} \mathcal{E}_{i 0 t}^{-2} d j=0
$$

which yields the following condition:

$$
\lambda_{i t} \mathcal{E}_{i 0 t}=\int_{0}^{1} \lambda_{j t} \mathcal{E}_{j 0 t} d j
$$

The above equation holds for all $i, j$ pairs, so that $\lambda_{i t} \mathcal{E}_{i 0 t}=\lambda_{j t} \mathcal{E}_{j 0 t}$. This equation holds when exchange rates are fixed. 